Thorax (1969), 24, 148.

\title{
Cardiac ventricular aneurysm
}

\author{
HUG H R. S. HAR L E Y
}

From Sully Hospital, Penarth, Glam.

\begin{abstract}
A case of successful excision of a ventricular aneurysm due to myocardial infarction is presented. The aetiology, incidence, pathogenesis, pathology, clinical features, and diagnosis of the condition are discussed. An account is given of the haemodynamic upset caused by aneurysms of the ventricle. The prognosis of untreated aneurysms is discussed. Although there is difference of opinion, it is concluded that a ventricular aneurysm adversely affects the prognosis after myocardial infarction. The indications for, and the mortality and results of, resection of ventricular aneurysms are discussed. The conclusion is drawn that persistent cardiac failure and angina can be relieved and the risk of systemic embolism reduced by the excision of expansile ventricular aneurysms of a fibrous nature. It is possible that excision may also reduce the incidence of subsequent acute myocardial infarction.
\end{abstract}

Ventricular aneurysm was first described in 1757 both by Hunter and by Dominicus Gusmanus Galeati. Sternberg (1914) made the first diagnosis during life. He is often quoted as being the first writer to recognize the condition of a chronic aneurysm, but Cruveilhier (1827) and Rokitansky (1842-1844) had both previously attributed chronic aneurysm to myocardial fibrosis. Sternberg (1914) forecast the possibility of radiological diagnosis and this was first achieved by Sézary and Alibert in 1922.

The first successful excision of an aneurysm was performed by Sauerbruch (1931) for an aneurysm of the right ventricle of unknown aetiology found unexpectedly at the time of operation. The first planned operation for a ventricular aneurysm was described in 1944 by Beck, who performed external reinforcement of an aneurysm of the left ventricle with pericardium and fascia lata. The first planned excision by a closed technique using clamps was reported by Likoff and Bailey in 1955, and the first open excision, using total cardiopulmonary bypass, was reported by Cooley, Collins, Morris, and Chapman in 1958. Since then there have been a number of reports of series of cases, or isolated cases, of open excision performed in this way. The first such report from Britain was by Telling and Wooler in 1961.

The case history is given here of a patient whose aneurysm following myocardial infarction was excised, and the condition is discussed with special reference to the role of surgery in its treatment.

\section{CASE HISTORY}

H.C. D., a 40-year-old furniture manufacturer, was seized by acute retrosternal pain and sweating at $\stackrel{\mathbb{D}}{\triangle}$ 8 a.m. on 6 October 1966. He was seen by his $\overrightarrow{\vec{\rho}}$ doctor, who gave him morphine. He was admitted to the Medical Unit, Cardiff Royal Infirmary, on 7 October. On examination a loud pericardial friction sound was heard all over the precordium, most prominent at the left sternal edge, but there was no evidence of either cardiogenic shock or left ventricular failure. Electrocardiography showed the features of panmural anterolateral myocardial infarction, including pathological $\mathrm{Q}$ waves and ST-segment elevation in leads S1, AVL, and V1 to V6 (Fig. 1). Radiological examination showed moderate cardiac enlargement and slight elevation of the left diaphragm with streaky opacities above it, but no evidence of left ventricular failure (Fig. 2). The serum $\alpha$-hydroxybutyrate dehydrogenase level was $1,560 / \mathrm{ml}$. (normal 120-260). The day after admission he developed signs $N$ of infection or infarction at the left base. $\mathrm{He}$ was treated with ampicillin and sedatives, but anticoagu- 0 lants were withheld because of the pericarditis. On 19 October 1966 he developed a right hemiplegia. O This recovered completely after a few days, except 0 for occasional aphasia for numbers. On 20 October deep vein thrombosis was diagnosed in the right calf, $\stackrel{\mathcal{D}}{\rightarrow}$ and a radiograph of the chest showed the changes of left ventricular failure (Fig. 3). Anticoagulation therapy was started with $100 \mathrm{mg}$. phenindione, and $\underset{\mathbb{D}}{\stackrel{D}{ }}$ continued with $50 \mathrm{mg}$. b.d., which was increased later $\stackrel{\odot}{\mathcal{P}}$ to $100 \mathrm{mg}$. b.d. In addition he received two doses of $\unrhd$ heparin $(10,000$ units) on the night of 21-22 October. Digoxin was administered from 26 October onwards 
because of features of left ventricular failure.

Radiological examination on 3 November showed a well-marked bulge projecting from the left margin of the heart in the postero-anterior view (Fig. 4), but the changes of left ventricular failure were less. A diagnosis of aneurysm of the left ventricle was made. It was decided that medical management should continue but that surgery should be considered in the future should left ventricular failure, or other debilitating symptoms, persist or should the aneurysm enlarge.

During his subsequent stay in hospital radiological, but no clinical, features of left ventricular failure persisted for a while and then abated. He was discharged on 8 December 1966 on digoxin, 0.25 mg. b.d., and phenindione, $100 \mathrm{mg}$. b.d. Postero-anterior and lateral radiographs of the chest taken on the day before discharge showed the anteriorly placed aneurysm clearly.

After discharge he complained of mild exertional dyspnoea and occasionally giddy attacks, especially shortly after getting into bed. He had three attacks of paroxysmal nocturnal dyspnoea. An attempt to omit digitalis was followed by a recurrence of left ventricular failure. Because of these features it was decided that the aneurysm should be excised.

He was admitted to Sully Hospital under the care of the writer on 16 September 1967. On examination he was a fairly fit man of 40 years. There was no clinical left ventricular failure, the blood pressure was $137 / 70 \mathrm{~mm}$. $\mathrm{Hg}$, and no abnormal physical signs were found in the cardiovascular system. Electrocardiography showed, in addition to pathological $Q$ waves in leads S1, AVL, and V4 and V5, the typical persistent ST-segment elevation and T-wave inversion in leads S1, AVL, and V4 to V6, and small $R$ waves over the left precordium, but the $R$ waves in lead AVR were not large (Fig. 5). The spatial vector was vertical, radiographs of the chest showed the anteriorly placed left ventricular aneurysm in both posteroanterior and lateral projections, together with moderate enlargement of the left ventricle and atrium (Figs 6a, b, and c). The aneurysm appeared to be about the size of a large orange, and on screening it showed obvious systolic expansion. The rest of the ventricular wall moved normally. The results of other relevant tests were as follows: S.G.O.T. 12, Hb $99 \%$, W.B.C. 6,700/cu. cm., P.C.V. $43 \%$. Platelet count 135,000. Blood film normal. Urine normal. Creatinine clearance $87 \mathrm{ml} . / \mathrm{min}$. Liver function tests showed no abnormality. The lung function and thrombotests were satisfactory.

On 26 September 1967 the aneurysm was excised using a bilateral anterior thoracotomy incision through the fifth intercostal spaces and the sternum. Total cardiopulmonary bypass was established for $\mathbf{8 0}$ minutes, the body temperature being reduced to $30^{\circ} \mathrm{C}$, and ventricular fibrillation was induced electrically before the aneurysm was excised. The left femoral artery and right atrium were cannulated for bypass, and the right brachial artery and the right median cubital and left saphenous veins for manometry of pressure in a proximal artery and in the superior and inferior venae cavae. The aorta and pulmonary artery were not taped because of adhesions in the transverse sinus. The pericardium was opened by a rectangular incision, the vertical limb lying in front of the right phrenic nerve and the transverse

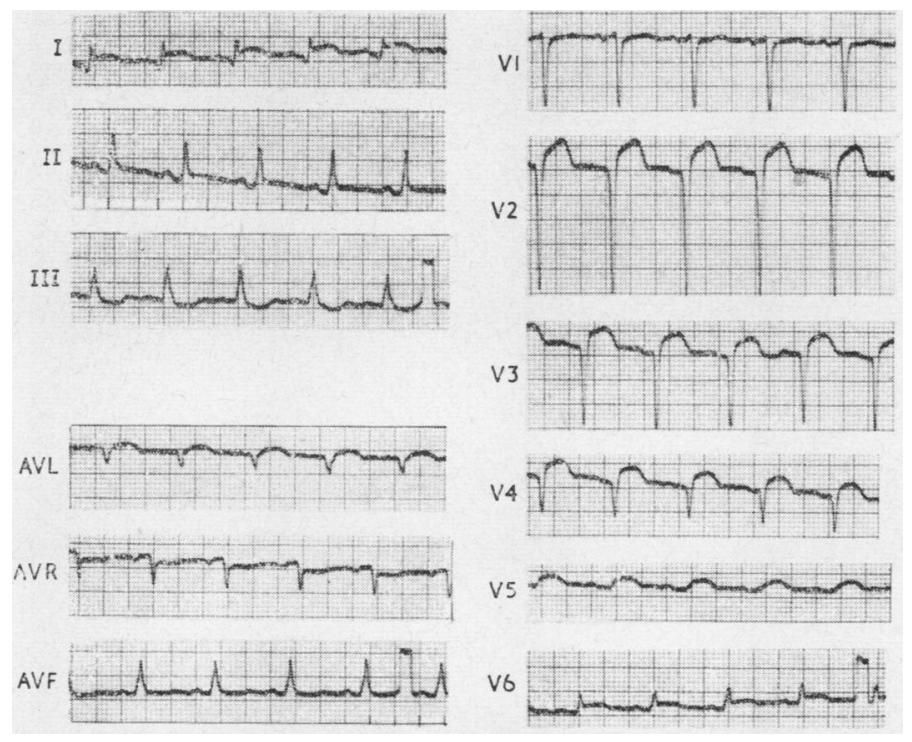

FIG. 1. E.C.G. taken on day of admission (7.10.65) shows features of antero-lateral myocardial infarction. 


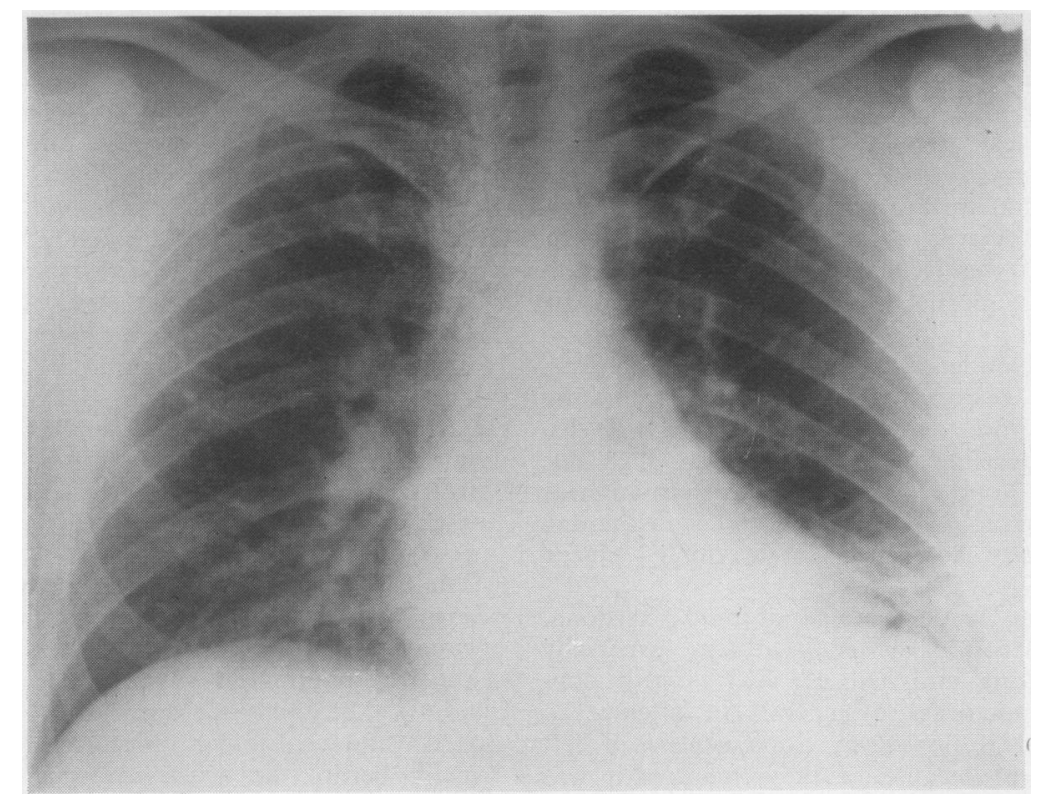

FIG. 2. Radiograph taken on day of admission shows streaky opacities above right diaphragm but no evidence of left ventricular failure.

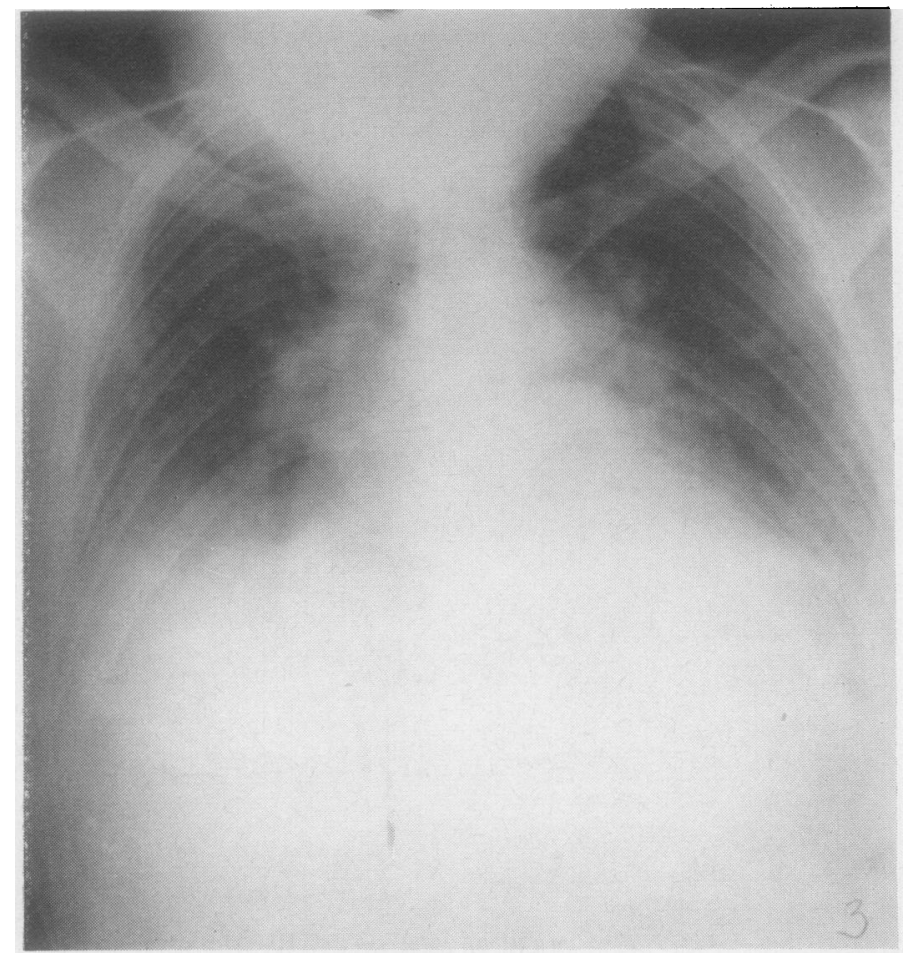

FIG. 3. Radiograph (20.10.66) shows changes of left ventricular failure. 
limbs running to the left from the upper and lower ends of the vertical limb. It was densely adherent over the region of the aneurysm. This incision enables the pericardium to be dissected off the right atrium and ventricle, and cannulation of the former to be performed for the establishment of bypass before the pericardium is dissected off the aneurysm. It may be advantageous to open the aneurysm before the adherent pericardium is dissected off it in order to reduce the risks of embolism and haemorrhage during the dissection, and to avoid the necessity of inserting a left ventricular cannula at this stage. Under the conditions of bypass a large aneurysm was seen which did not pulsate and which appeared to occupy most of the left ventricle. It was difficult to distinguish between the aneurysmal and non-aneurysmal portions of the ventricle. The ventricles were fibrillated electrically and an incision was then made through the centre of the aneurysm. Its wall was composed of tough fibrous tissue, with very small amounts of muscle tissue near its margin, and its cavity contained considerable amounts of thrombus. The latter was carefully evacuated from the aneurysm and left ventricle with a forceps and a sucker, and the left atrium was then sucked out and carefully inspected through the mitral valve. No thrombus was found in it. The view of the aortic and mitral valves was exceptionally good. Both valves were normal. When all thrombus had been removed it was easy to feel the junction between the fibrotic wall of the aneurysm and the muscular wall of the rest of the ventricle. The wall of the aneurysm was thinner than, and of a completely different consistency from, the surrounding myocardium, and the junction between the two was well defined. After the aneurysm had been opened it was obvious that it occupied the antero-lateral aspect of the left ventricle, and that the unaffected portion of the ventricle was of good size. The aneurysm was then excised, leaving a one-centimetre rim of fibrous tissue around its periphery for the insertion of sutures. The ventricle was closed with a layer of horizontal mattress sutures passed through two strips of Teflon felt and the residual fibrous rim of the aneurysmal wall, and this layer was reinforced with a continuous over and over suture which also passed through the Teflon strips. A few extra interrupted sutures were required at the upper end of the suture line. A cannula was brought out through the lower end of the incision to decompress the left ventricle. Sinus rhythm returned spontaneously during excision of the aneurysm. No haemorrhage occurred from the suture line, and when the heart beat was strong the cannula was removed from the left ventricle. The heart came off bypass easily with the support of only a single injection of $0.25 \mathrm{ml}$. adrenaline $1: 80,000$ given into the right ventricle. Drainage tubes were placed in the pericardium and in both pleural cavities, and the chest wall closure was reinforced with two wire sutures through the sternum and three pericostal sutures of catgut on each side. The exposure provided by the bilateral thoracotomy incisions was excellent.

The haemodynamic recovery from the operation was smooth and uneventful. Forty-eight hours after operation he developed a monoplegia of the left arm. The arm and forearm recovered rapidly, the hand more slowly, especially thumb movements and wrist extension. He was discharged on 2 November 1967. He was very well, had no congestive heart failure, and was in sinus rhythm, with a blood pressure of $128 / 80 \mathrm{~mm}$. Hg. The heart sounds were normal. Radiographs of 20 October 1967 showed the heart to be definitely smaller than before the operation and

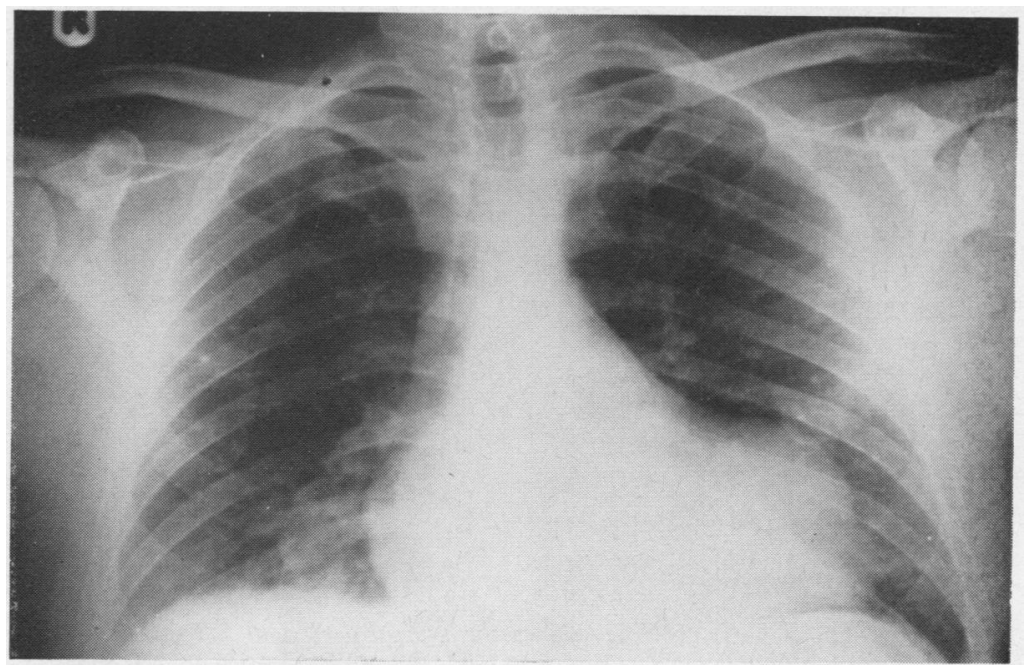

FIG. 4. Radiograph (3.11.66) shows left ventricular aneurysm. The features of left ventricular failure are less marked. 
the electrocardiogram of 11 October 1967 (Fig. 7) showed changes similar to those before the operation, but the segment elevation was less marked.

Pathological examination of the resected specimen showed dense collagenous fibrosis with occasional islands of necrotic myocardium (Fig. 8). There was laminated mixed thrombus of fairly recent appearance.

His subsequent progress has been excellent, and when last seen at the beginning of June 1968 he was very well and had no complaints, and there were no abnormal physical signs in the cardiovascular system. A postero-anterior radiograph showed the heart to be much smaller than before the operation, and there was no evidence of left ventricular failure (Fig. 9) even though he was not on digitalis. Phenindione has also been omitted.

\section{AETIOLOGY}

SEX Men are affected by ventricular aneurysm following myocardial infarction about four times $\frac{\bar{\omega}}{\mathrm{s}}$ more often than women, whereas the ratio for $\mathbb{D}$ myocardial infarction without aneurysm is only about 2 or 2.5 to 1 . Thus Schlichter, Hellerstein, and Katz (1954) found that nearly four-fifths of $\vec{\circ}$ all such aneurysms occurred in men. Abrams, $\overrightarrow{\vec{\omega}}$ Edelist, Luria, and Miller (1963) found that in their 65 cases of ventricular aneurysm men were $\overrightarrow{\vec{x}}$ affected four times more often than women, $\stackrel{x}{\sim}$ whereas the sex ratio in favour of men for myo- + cardial infarction was only 1.9 to 1 . Dubnow, $\stackrel{N}{-}$ Burchell, and Titus (1965) found that $81 \%$ of their $\vec{\infty}$ 80 patients with ventricular aneurysm following 을

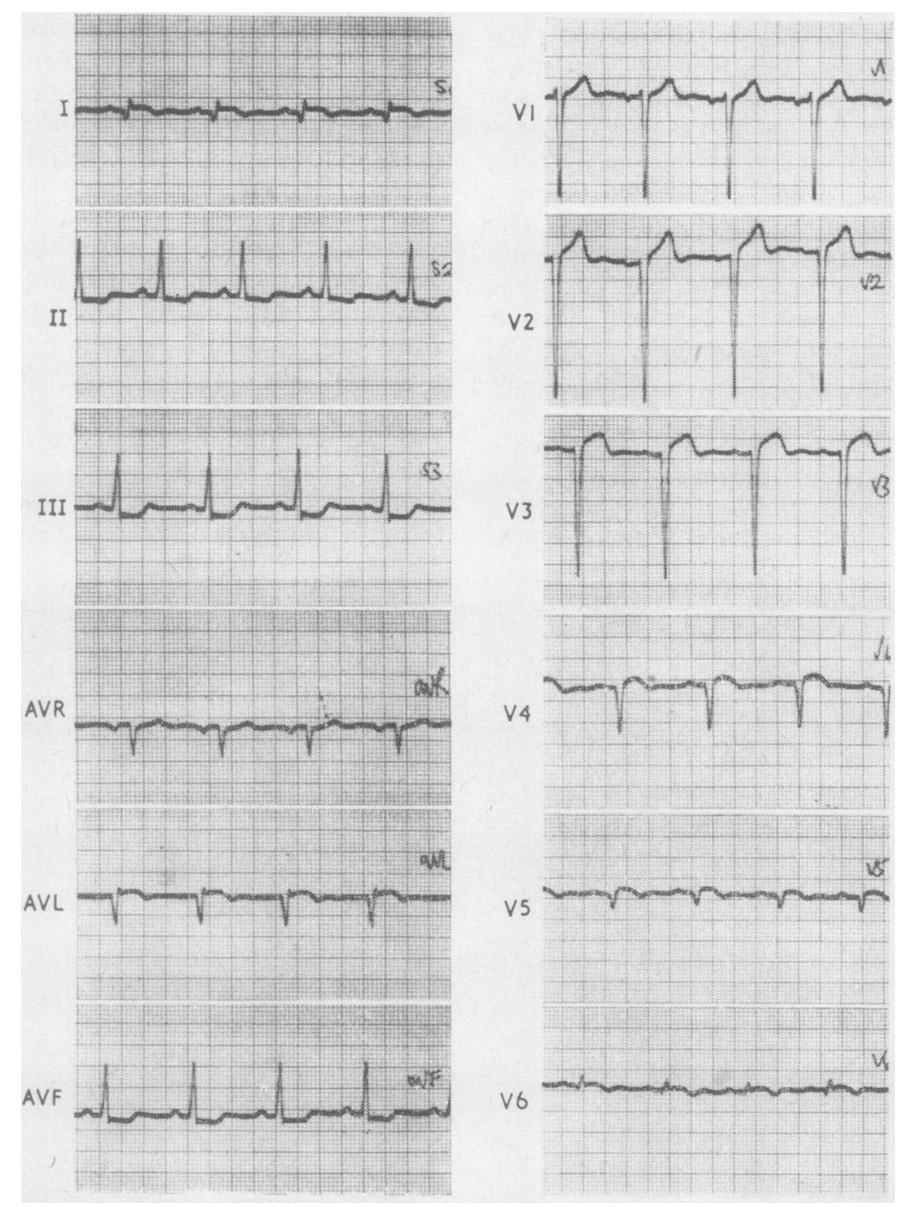

FIG. 5. E.C.G. (18.9.67) shows the typical persistent S.T.-segment elevation and $T$-wave inversion in leads $S 1, A V L$, and V4 to V6, and small $R$ waves over the left precordium, but no enlargement of the $R$ waves in lead $A V R$. 


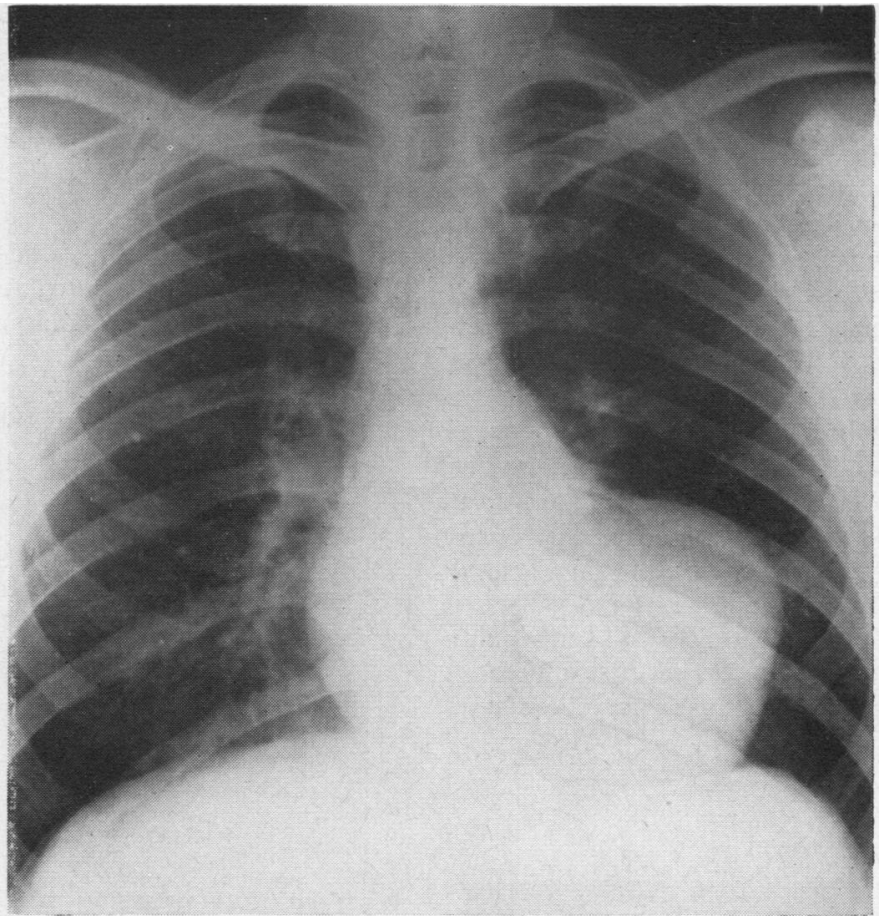

FIG. $6 \mathrm{a}$

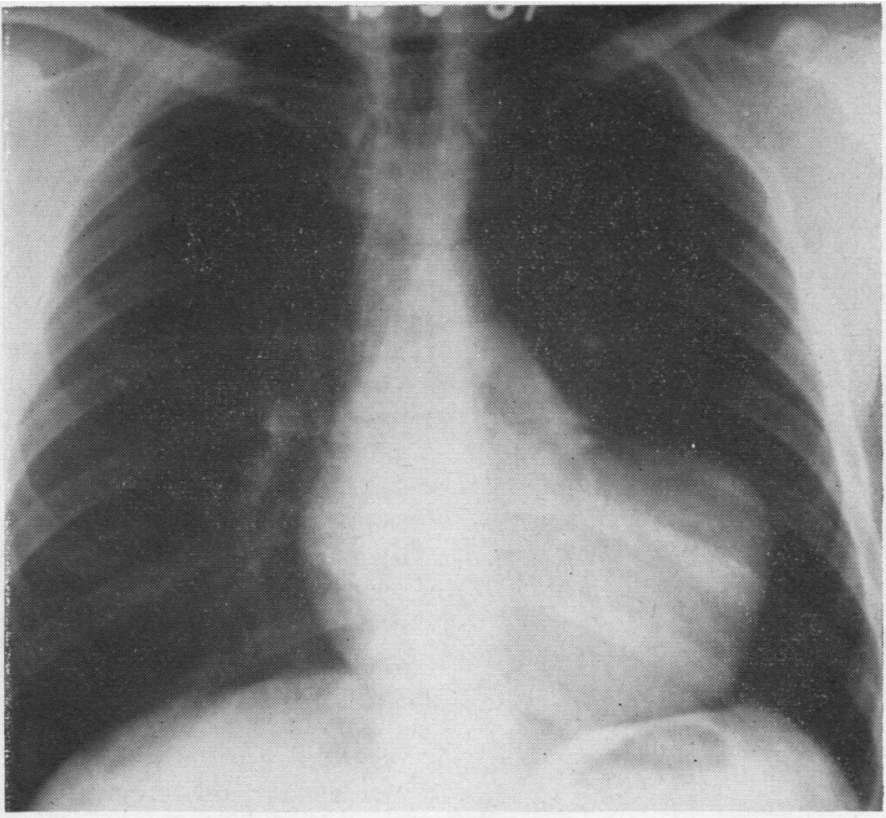

FIG. $6 \mathrm{~b}$

Legends to Figs $6 a$ and $6 b$ are on page 154 
myocardial infarction were men, whereas the sex ratio in favour of males for myocardial infarction was $2 \cdot 5$ to 1 .

AGE Most ventricular aneurysms following myocardial infarction occur between the ages of 45 and 70 years, but no age is exempt. Robicsek, Dickson, Parke, Daugherty, and Sanger (1966) reported the case of a baby boy who developed myocardial infarction at the age of 5 weeks which caused an aneurysm of the left ventricle that was successfully excised at the age of 4 years. Of the 102 patients of Schlichter et al. (1954) $72.5 \%$ were aged between 55 and 74 years, but Schlichter himself saw a ventricular aneurysm in an infant of $2 \frac{1}{2}$ months caused by an anomalous left coronary artery originating from the pulmonary artery.

EXCITING CAUSES The aetiology of ventricular aneurysms was discussed in detail by Schlichter et al. (1954) and others. The causes may be classified as follows:

1. Congenital

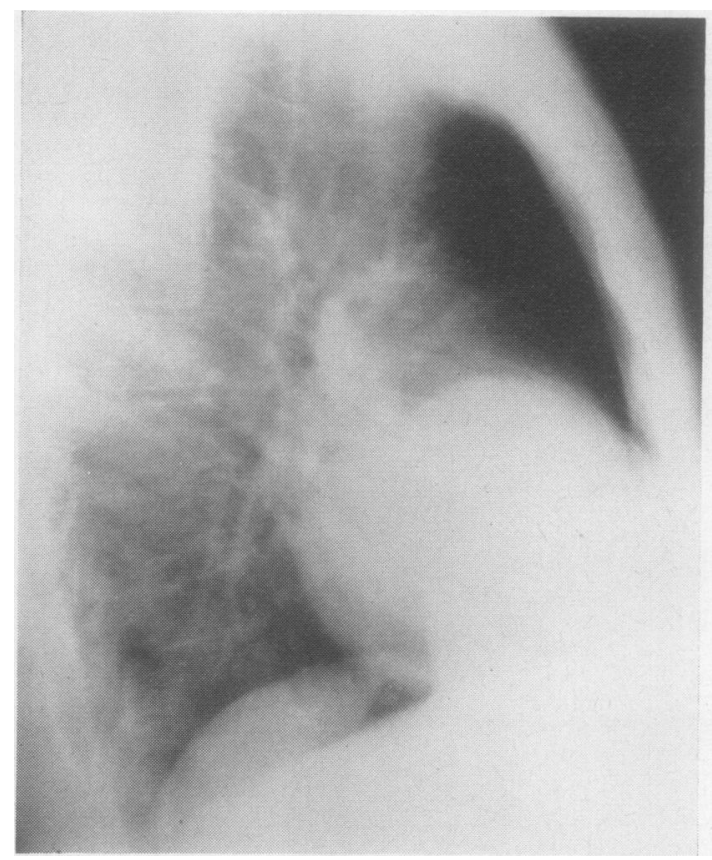

FIG. 6c

FIGS $6 a, b$, and c. Radiographs (18.9.67), after readmission for surgery, show the anteriorly placed aneurysm together with moderate enlargement of the left ventricle and left atrium.
2. Acquired

(a) Ischaemic (myocardial infarction)

(b) Traumatic

1. Accidental wounds Closed Open

2. Surgical wounds Closed cardiac operations Open cardiac operations

(c) Infective

1. Rheumatic fever

2. Syphilis

3. Tuberculosis

4. Infective endocarditis, with resultant myocardial abscess; especially with $\stackrel{ }{\Im}$ mycotic coronary arteritis.

5. Septic embolus (e.g., in subacute bacterial endocarditis)

6. Polyarteritis

(d) Idiopathic

\section{PREDISPOSING FACTORS}

SYSTEMIC HYPERTENSION Schlichter et al. (1954)

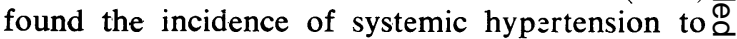
be $67.6 \%$ in their series, twice as great as that $\overrightarrow{\overrightarrow{0}}$ found by Mintz and Katz (1947), namely $35.9 \%$, 3 for patients with myocardial infarction but without aneurysm, studied in the same hospital and using the same criteria for hypertension. The incidence of systemic hypertension found in the 으 aneurysm series (as also in the other series) was higher in women $(86.4 \%)$ than in men $(62.5 \%)$. Only 3 of the 22 women were not hypertensive. In contrast with the figures of Schlichter et al. (1954) 8 are those of Dubnow et al. (1965), who found an $₹$ incidence of $29 \%$ in 80 necropsy cases, and of 을 Gorlin, Klein, and Sullivan (1967), who found $D$ hypertension in only 6 out of 24 patients investi- 을. gated clinically. On the basis of their respective $\bar{N}$ findings Schlichter et al. (1954) stressed the of importance of systemic hypertension as an aetio- $\tilde{O}$ logical factor in the development of ventricular స్ట aneurysms, whereas Dubnow et al. (1965) were unable to draw any conclusions.

A high intraventricular pressure would be expected to encourage the development of an aneurysm in a functionless portion of the 0 ventricular wall, and this is supported by the high incidence of post-operative right ventricular hyper- $\mathbb{D}$ tension in patients developing aneurysms of the $\mathbb{\mathbb { D }}$ right ventricle after surgery (see iatrogenic traumatic aneurysms). 
DIABETES MELlitus This is known to have a correlation with ischaemic heart disease and is common in patients suffering from ventricular aneurysms. It occurred in $22.5 \%$ of the patients of Schlichter et al. (1954), in 24 of the 65 patients of Abrams et al. (1963), and in 16 of the 24 patients of Gorlin et al. (1967). Abrams et al. (1963) state '. . . a ventricular aneurysm should be particularly considered in diabetic patients, especially men, with cardiomegaly and a history of myocardial infarction'. As in the case of hypertension, Schlichter et al. (1954) found that the incidence of diabetes was higher in women $(41 \%)$ than in men $(17.5 \%)$. Only one of their 22 women had neither hypertension nor diabetes.

VALVE DISEASE Schlichter et al. (1954) found that 27 of their 102 patients had significant deformities of heart valves, an incidence higher than that for myocardial infarction. They suggested that the strain caused by these lesions contributed to the development of aneurysm.

BED REST Schlichter et al. (1954) found that of 82 patients with relevant details $39 \%$ had had no bed rest after their myocardial infarction, and that $31.7 \%$ of them had had bed rest for three weeks or less. They considered that these figures were significant, and that a short or absent period of bed rest predisposed to the development of a ventricular aneurysm. They advised bed rest for four weeks or more for all large or transmural infarcts. This view has been quoted by a number of subsequent writers on the subject of ventricular aneurysm, but Dubnow et al. (1965) found no correlation between lack of bed rest and the development of an aneurysm in their patients, and Telling and Wooler (1961), after studying pub-

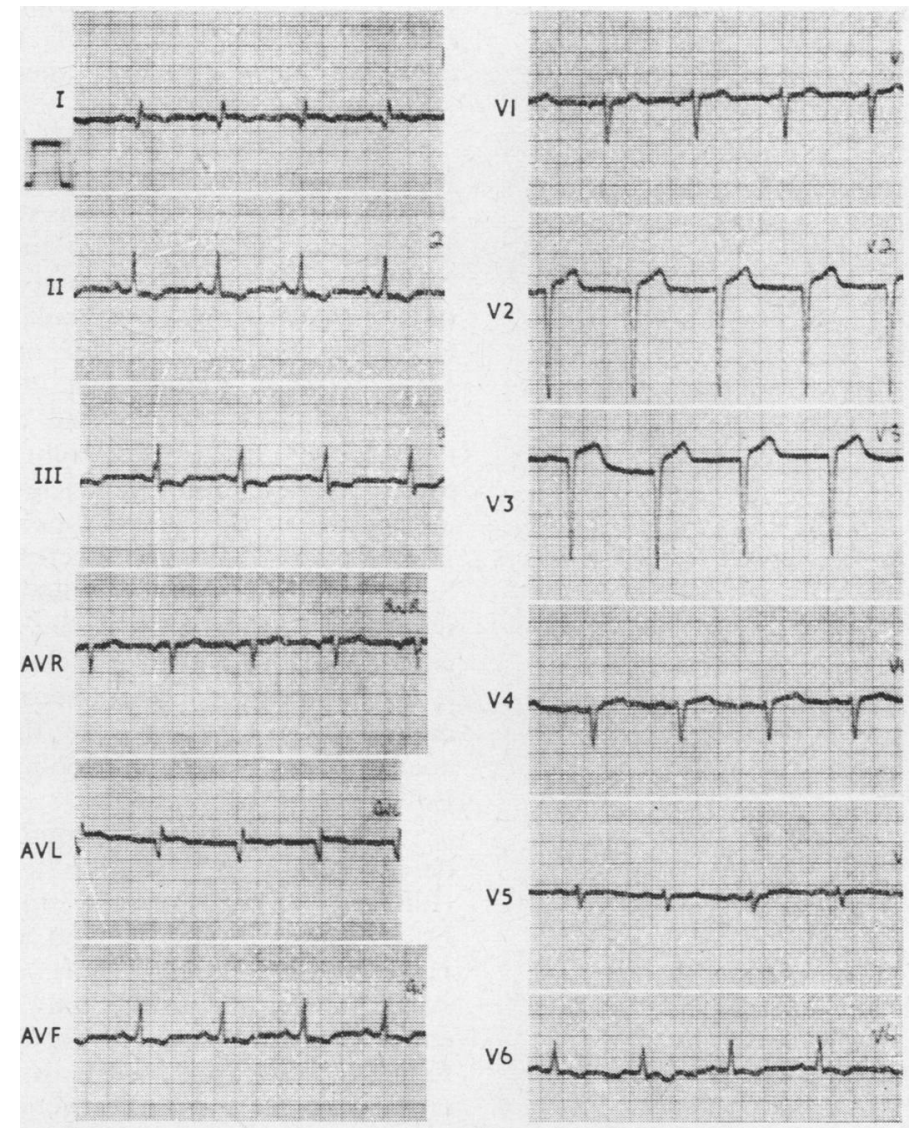

FIG. 7. E.C.G. 15 days after operation (11.10.67). The changes are similar to those before the operation, but the segment elevation is less marked. 
lished case reports where sufficient detail was given, came to the conclusion that the hypothesis that inadequate rest was a major cause of aneurysm was not supported by the evidence. More than one half of the patients of Dubnow et al. (1965) had had bed rest for three weeks or more. The role of the period of bed rest seems to be open to doubt.

The above analysis suggests, but does not prove, that any cause of ventricular stress accompanying or following panmural infarction of the ventricular wall predisposes to the formation of an aneurysm. Thus patients who are afflicted by panmural infarction and who suffer from systemic hypertension or valvar disease are, perhaps, predisposed to the development of an aneurysm of the left ventricle. Likewise aneurysms are liable to develop in the right ventricle after surgery when right ventricular hypertension persists after the operation. Diabetes mellitus appears to be a common concomitant of ventricular aneurysm.

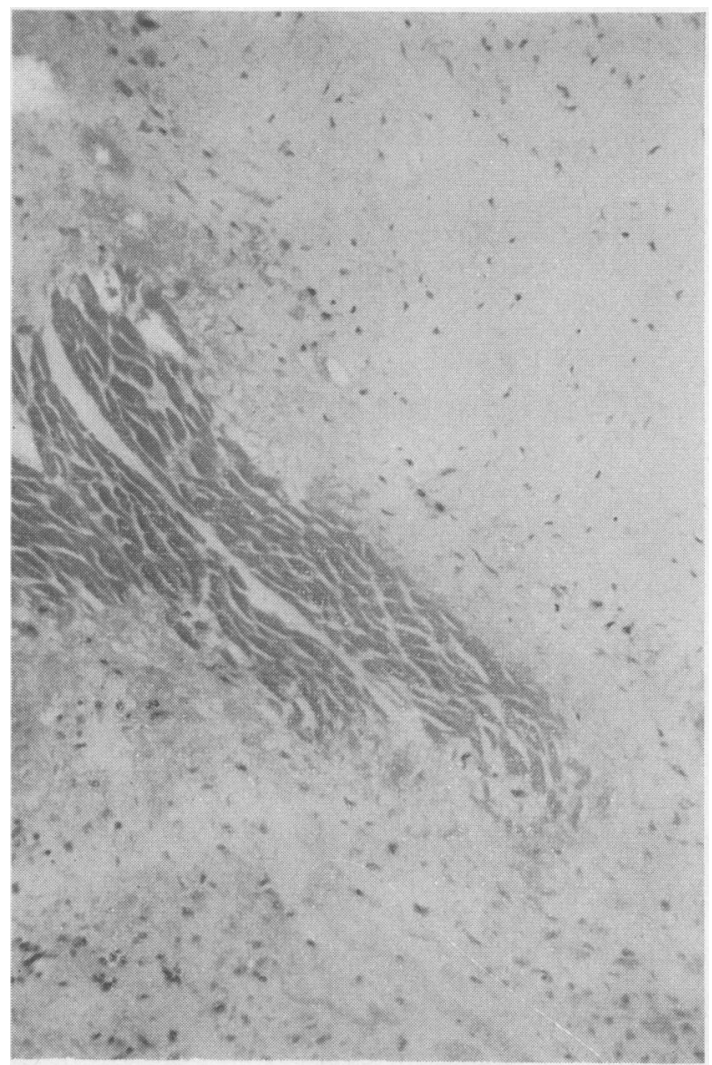

FIG. 8. Section of resected specimen stained with haematoxylin and eosin, showing an 'island' of necrotic cardiac muscle in dense collagen. $\quad \times 120$.
AETIOLOGICAL TYPES OF VENTRICULAR ANEURYSM

CONGENITAL ANEURYSM This is very rare in either ventricle. Congenital aneurysms of the right ven- $\overline{\bar{\omega}}$ tricle have been reported by Björk (1964) and by $\underset{\nabla}{\overparen{ }}$ Miller, Lowenthal, Krause, and Rosenblum (1953). A congenital aneurysm of the apex of the left ventricle was reported by Björk (1964). This $\overrightarrow{0}$ aneurysm was thin-walled and completely separa- $\overrightarrow{-}$ ted from the remaining part of the left ventricle $\vec{\sigma}$ by a wall of fibrous tissue, but it was full of unclotted blood.

ANEURYSM CAUSED BY MYOCARDIAL INFARCTION DUE TO CORONARY ARIERIAL DISEASE Myocardial infarc- $\vec{\infty}$ tion accounts for $85 \%$ to $90 \%$ of all ventricular ${ }^{\infty}$ aneurysms (Schlichter et al., 1954 ; Telling and Wooler, 1961). They are especially likely to occur $\vec{z}$ after large transmural infarcts associated with pericarditis. In all 40 of the necropsy cases $\frac{\widehat{\rho}}{\supset}$ reported by Phares, Edwards, and Burchell (1953) $\vec{c}$ the infarct was transmural. Infarction was the cause of 63 out of the 65 aneurysms reported by Abrams et al. (1963).

The majority of ischaemic aneurysms affect the left ventricle. The rarity of ischaemic aneurysm $\overline{\bar{O}}$ of the right ventricle was stressed by Stansel, 요 Julian, and Dye (1963), who quote Appelbaum and $\stackrel{\mathbb{Q}}{\circ}$ Nicolson (1935) as finding only one in $56 \overrightarrow{\overrightarrow{0}}$ necropsy cases of ventricular aneurysm, Legg (1884) as finding 3 in 90 necropsy cases, and Hall (1903) as finding one in 112 cases. Of the 102 necropsy cases reported by Schlichter et al. (1954), one involved the right ventricle only and three affected both ventricles, whereas all th: aneurysms in the 80 necropsy cases reported by Dubnow et al. (1965) affected th: left ventricle. Summing these figures of 440 aneurysms due to myocardial ischaemia, only six $(1.4 \%)$ were confined to the right ventricle.

Most left ventricular aneurysms due to myo- $D$ cardial infarction occur in the anterior wall or을. apex of the ventricle (Schlichter et al., $1954 ; \mathrm{N}$ Edwards, 1961 ; Dubnow et al., 1965 ; Gorlin et al., 1967) in the territory supplied by the anterior $N$ descending branch of the left coronary artery (Lillehei, Levy, DeWall, and Warden, $1962: 0$ Effler, Westcott, Groves, and Sully, 1963 ; Cooley Hallman, and Henly, 1964). According to Effler et al. (1963) this is the only site where a large? enough area of muscle replacement by fibrous $\square$ tissue is compatible with an adequate collateralo circulation, and with restriction of infarction to the ventricular wall alone, so allowing both $\underset{\mathbb{Q}}{\mathbb{Q}}$ survival of the patient and the development of an $\sigma$ aneurysm. In the series of 82 aneurysms occurring 
in 80 necropsy patients studied by Dubnow et al. (1965), 79\% of the aneurysms were situated in the anterior wall or apex of the left ventricle, and 31 of the 40 aneurysms studied at necropsy by Phares et al. (1953) occurred at the same sites (Edwards, 1961).

The incidence of ventricular aneurysm after myocardial infarction reported in the literature varies between $3.5 \%$ and $38 \%$ (Schlichter et al., 1954 ; Lillehei et al., 1962 ; Cooley et al., 1964 ; Dubnow et al., 1965). This wide variation in reported frequency depends upon the type of study (necropsy or clinical) and on the definition of an aneurysm (Dubnow et al., 1965). Schlichter et al. (1954) found an incidence of ventricular aneurysm at necropsy of $15 \%$ among 2,273 cases of myocardial infarction, and in $20 \%$ of their own 512 cases of infarction. Abrams et al. (1963) found a necropsy incidence of aneurysm of $12.4 \%$ in 508 cases of infarction and Dubnow et al. (1965), using the definition of a ventricular aneurysm given by Edwards (1961), one of $3.5 \%$ in 2,293 necropsies.

All the reported figures for the incidence of ventricular aneurysm after myocardial infarction, except those of Dubnow et al. (1965), are $5 \%$ or higher, and more than one half of them exceed
$10 \%$. This incidence is, I believe, higher than most physicians realise, perhaps because previously there has been little possibility of effective surgical treatment, and the diagnosis was not considered to be of great importance from a therapeutic standpoint.

TRAUMATIC ANEURYSMS Traumatic aneurysm may be true or false (vide infra). Such aneurysms are very rare in either ventricle after accidental trauma, whether open or closed (Joachim and Mays, 1927 ; Lyons and Perkins, 1958 ; Kerr, Wilcken, and Steiner, 1961 ; Stansel et al., 1963 ; Panday, Parulkar, Kelkar, and Sen, 1965). Harken (1946) found no aneurysm among 56 patients with war wounds close to the heart, even though in 13 instances the missile was found within a cardiac chamber. Aneurysms following closed injuries have been reported by Bright and Beck (1935) and Barber (1944). A calcified aneurysm of the left ventricle following a stab wound was reported by Lyons and Perkins (1958), and an aneurysm of the left ventricle following its accidental incision during the exposure of the heart for open cardiopulmonary resuscitation in a case of cardiac arrest was reported by Panday et al. (1965). Vasiljevic, Antic, Tomic, Anojcic, and Prokic

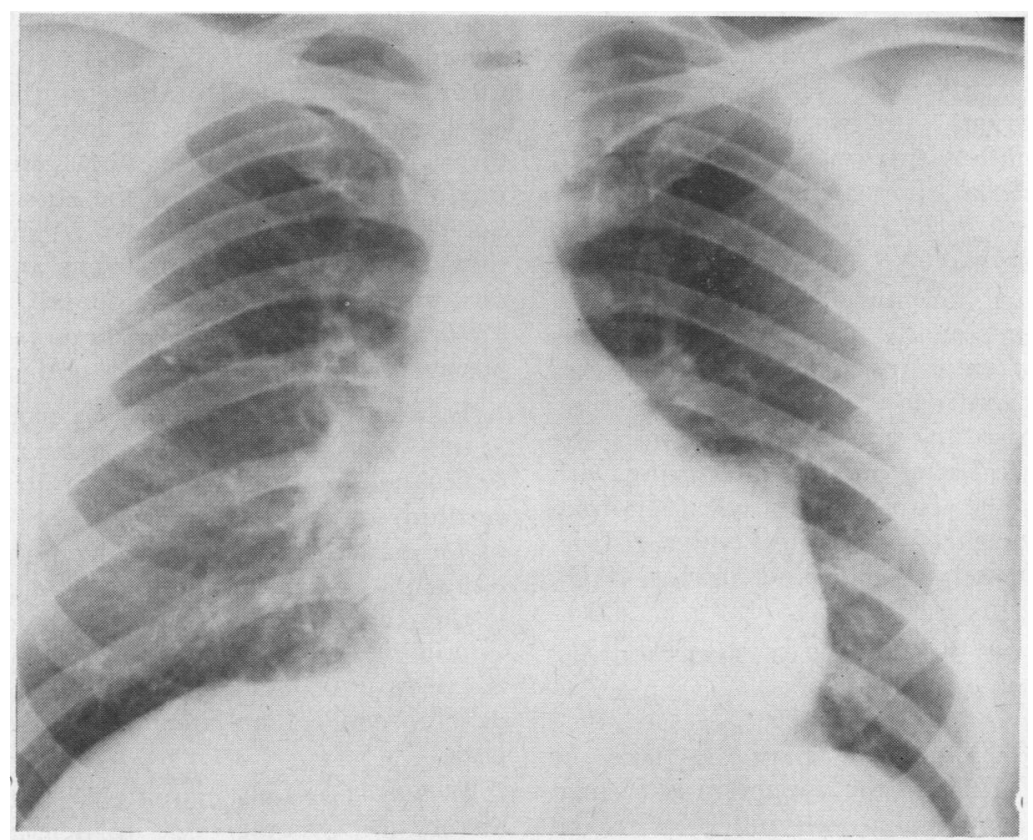

FIG. 9. Radiograph four months after excision of the aneurysm (22.1.68). The heart is much smaller and there is no evidence of left ventricular failure. 
(1959) and Stansel et al. (1963) reported aneurysms of the right ventricle after accidental open injuries.

Iatrogenic ventricular aneurysm following closed or open operations on the heart is also rare (Kerr et al., 1961 ; Panday et al., 1965) but is occurring with increasing frequency. Surgery is the most important cause of aneurysm of the right ventricle (Stansel et al., 1963). These occur especially after closed operations on the pulmonary infundibulum or valve in cases of Fallot's anomaly, because right ventricular hypertension always persists despite the operation, or after closed operations for pulmonary stenosis, if the pressure in the right ventricle remains high because of inadequate valvotomy (Kerr et al., 1961; Stansel et al., 1963). Aneurysms of this nature have been reported by McCord and Blount (1955), Dubost (1955), Derra and Loogen (1959), Fatti (1959, quoted by Kerr et al., 1961), Špaček, Bergmann, and Dejdar (1959), Kerr et al. (1961), and Campbell, Deuchar, and Brock (1954). Aneurysms of the left ventricle following closed aortic valvotomy have been reported by Segel, Fatti, Adler, and Crawshaw (1957, 2 cases) and Kerr et al. (1961, 2 cases), and after closed mitral valvotomy by Smithy, Boone, and Stallworth (1950), Smith, Goldberg, and Bailey (1957), and Kerr et al. (1961).

INFECTIVE ANEURYSM This is rare, and a list of reported causes is given above. The writer has operated on a patient with two aneurysms of the left ventricular outflow tract which were presumed to be due to bacterial endocarditis.

IDIOPATHIC ANEURYSM An unusual aneurysm of the left ventricle of unknown aetiology occurs in Africans and, occasionally, in white people. This takes the form of an annular subvalvar aneurysm affecting the left ventricle close to the mitral ring. It often gives rise to mitral regurgitation, by stretching the mitral ring and by interfering with the function of the papillary muscles, chordae tendineae, and cusps of the mitral valve (Lurie, 1960 ; Pocock, Cockshott, Ball, and Steiner, 1965).

\section{DEFINITION AND PATHOLOGICAL TYPES OF ANEURYSM}

Aneurysm of the ventricle may be true or false (Kerr et al., 1961). True aneurysm is formed by a part of the ventricular wall and gives rise to a localized outpouching of the ventricle. Edwards (1961) defined such a ventricular aneurysm as 'a protrusion of a localized portion of the external $\stackrel{\bar{s}}{+}$ aspect of the ventricle beyond the remainder of the cardiac surface with simultaneous protrusion of the cavity as well'. Edwards did not include as $\frac{\bar{\omega}}{\vec{D}}$ an aneurysm cases of healed myocardial infarc- $\stackrel{\mathbb{Q}}{\Omega}$ tion in which considerable thinning of the muscle $ळ$ causes localized dilatation of the ventricular chamber, but without a change in shape of the external surface. Gorlin et al. (1967) have recently $\overrightarrow{\vec{\omega}}$ given a functional definition of an aneurysm due $O$ to myocardial infarction as an abnormality of $\vec{x}$ local movement of the ventricular wall, whether is or not associated with thinning or fibrosis. The abnormality of movement (asynergy) may be characterized by absence of movement (akinesis) $\stackrel{\triangleright}{\infty}$ or paradoxical systolic expansion (dyskinesis). 은 These abnormalities of movement, according to Gorlin et al., may occur as the result of a classical $\overrightarrow{3}$ fibrotic aneurysm or a functional muscular aneurysm (vide infra). This definition presents two $)$ features of difficulty, at least from the point of $\vec{\bullet}$ view of surgery. The first is that infarction is often $\stackrel{\circ}{0}$ followed by similar abnormalities of movement, which may be reversible, but without aneurysm formation, and the second is that by this definition the walls of some aneurysms are composed of normal appearing muscle, with little or no fibrous tissues. Aneurysms suitable for surgical excision should be composed of fibrous tissue.

A false aneurysm lies outside the heart and communicates with the cavity of the ventricle through a small perforation of the myocardium, usually caused by injury or infection. Blood leaks through this perforation, but is contained by an $\underset{x}{\stackrel{0}{\vec{N}}}$ inflammatory reaction of the surrounding tissues. Such an aneurysm is really a pulsating haematoma. The containing adhesions are at first fibrinous, but later they become densely fibrous, so that the walls of true and false aneurysms may be im- 0 possible to distinguish, even with a microscope.

Traumatic aneurysm may be true or false (Kerr et al., 1961), whereas other types are usually true. N True aneurysm results when an area of the myocardium is congenitally weak, or when softening $N$ of an area of myocardium occurs as the result of $\underset{\omega}{N}$ ischaemia or inflammation. The weakened area 0 is then blown out into an aneurysm by the con-co tinuous action of the intra-ventricular pressure. A high intra-ventricular pressure favours the $\stackrel{?}{+}$ development of an aneurysm, as will be evident 0 later.

It was previously thought that all traumatic $\stackrel{\circledR}{\circledR}$ aneurysms, whether due to accident or surgery, $\stackrel{\mathbb{Q}}{\varrho}$ were false (Bailey, Bolton, Nichols, and Gilman, $\overline{2}$ 1958), but as the result of work by Smithy et al. 
(1950) and Kerr et al. (1961) it is now recognized that they may be either true or false. Traumatic true aneurysm can be explained by the occurrence of infarction around the area of injury (Kerr et al., 1961). In hearts already damaged by disease interstitial haemorrhage and oedema following instrumentation may devitalize surrounding muscle fibres and so produce a small infarct which will lead to the subsequent development of a true aneurysm. Infarcts occurring in this way, accompanied by electro-cardiography or necropsy evidence of infarction, were described by Segel et al. (1957) and Kerr et al. (1961) after closed transventricular aortic valvotomy. An example of a traumatic true aneurysm has also been reported by McCord and Blount (1955).

The health of the myocardium before the time of injury is probably pertinent to the production of infarction, while the intra-ventricular pressure is probably important to the subsequent development of a traumatic aneurysm, whether true or false. The truth of the latter statement is well illustrated by the occurrence of aneurysms of the right ventricle after surgery. Of five such cases reviewed by Kerr et al. (1961), four developed after closed operations for Fallot's anomaly, in which the right ventricular pressure always remains high after surgery, while the fifth occurred after closed valvotomy for pulmonary stenosis in a patient in whom the right ventricular pressure also remained high after the operation. The low pressure normally present in the right ventricle may partially explain the rarity of aneurysm of this ventricle after myocardial infarction.

False aneurysms result from partial breakdown of sutured wounds of the heart, whether the wounds be surgical or accidental. Bailey et al. (1958) considered that this was due to sutures being inserted through only a part of the thickness of the ventricular wall, so permitting dissection of the wall of the ventricle to occur, but the more likely explanation for these aneurysms is that they result from ischaemic or infective necrosis, due either to strangulation by sutures tied too tightly or to superadded infection. Meticulous care in suturing wounds or incisions in the ventricles is essential. Traumatic false aneurysms have been reported by Smith et al. (1957), Lyons and Perkins (1958), and Panday et al. (1965).

\section{THE HEALING OF VENTRICULAR WOUNDS}

This process was studied experimentally in dogs by Thomas and Ziffren (1952) and by Warren, Muller, East, and Sosa (1958). A zone of necrosis occurs adjacent to the suture line. In wounds that do not break down this zone is completely invaded by granulation tissue with the production of a scar in two to three weeks. This scar at first has the same thickness as the wall of the left ventricle, but if the incision is more than $2 \mathrm{~cm}$. long thinning and stretching of the scar occurs after about one month, even if no visible coronary vessels are divided, so that its thickness becomes reduced to one half or less of that of the ventricular wall. This thinning does not occur after shorter incisions. If large incisions are made in the wall of the right ventricle, without regard for the branches of the right coronary artery, constant myocardial thinning occurs between the incision and the interventricular septum (Warren et al., 1958).

Ventricular wounds heal best when the sutures take the whole thickness of the ventricular wall without damaging coronary arterial branches, when they are tied just tight enough to maintain haemostasis, but without causing ischaemic necrosis of the aajacent myocardium, and when their number is the minimum required to maintain adequate apposition of the wound edges.

MORBID ANATOMY AND HISTOLOGY OF VENTRICULAR ANEURYSMS DUE TO MYOCARDIAL INFARCTION

Two to three months after myocardial infarction the wall of a classical true aneurysm is composed of dense collagenous or hyaline fibrous tissue (Lillehei et al., 1962) which is tough but thinner than the wall of the left ventricle from which it arises. Sometimes there are a few muscle fibres surrounded by scars or foci of mononuclear or macrophagic cells, representing the remnants of a previous stage of acute inflammation. In the writer's case only occasional islands of necrotic myocardium were seen (Figure 8). In many cases of true aneurysm all the muscle fibres are completely replaced by fibrous tissue and it is then impossible to say whether the aneurysm is true or false. Dubnow et al. (1965), however, were able to demonstrate residual bundles of muscle fibres in most of their cases at necropsy, and they found scarring of a papillary muscle in one third of the cases, though in none of these was the base of the papillary muscle incorporated into the aneurysm.

According to Gorlin et al. (1967), not all aneurysms are formed of fibrous tissue with thinning of the wall relative to the rest of the ventricle. Of 24 living patients investigated by them 7 were of this variety, but 7 others had full-thickness aneurysmal walls composed of both normalappearing muscle and fibrous tissue, while in 2 others the wall of the aneurysm was composed 
only of muscle tissue, which looked normal on examination both macroscopically and with the light microscope. Neither of these aneurysms contained any scar tissue and both exhibited paradoxical systolic expansion. These workers therefore found that aneurysms following myocardial infarction may be fibrous, fibro-muscular or muscular.

Gorlin et al. (1967) stated that either akinesis (absence of movement) or dyskinesis (systolic expansion) can occur with aneurysms, whether the wall is formed by a thin scar, or whether it is of normal thickness and composed of a mixture of 'normal' muscle and scar tissue, or of 'normal' muscle only. In both their cases in which the wall of the aneurysm was of full thickness and composed of normal-looking muscle, without scar tissue, the clearance of ${ }^{85}$ Krypton was normal and the muscle bled freely when incised. Why this normal-looking muscle did not contract is not known, but Gorlin et al. (1967) suggested that repeated sublethal episodes of ischaemia may destroy sensitive structures essential for excitationcontraction coupling and yet spare the contractile protein matrix itself. Thus damage to the Purkinje system, to membrane potential propagation, or to the sarcotubular system could block proper or full activation of contraction and yet leave the muscle normal to light microscopy.

Only if muscle shows true paradox can it be said to be non-contractile. Simple lack of expansion during systole implies either enough tension development in the area to resist transmitted intracavitary forces or the replacement of muscle by rigid fibrosis. It appears that an aneurysm, the wall of which is formed by scar tissue, may or may not show systolic expansion, according to the rigidity of the scar, and that systolic expansion can also arise in association with an area of muscle which is non-contractile but normal when examined with a light microscope.

A ventricular aneurysm may be diffuse or saccular, and the latter variety may have a wide or a narrow neck. Infarctive aneurysms vary greatly in size. They may measure only 2 or $3 \mathrm{~cm}$. in diameter or be larger than the heart itself (Schlichter et al., 1954), and they may be single or multiple. Thus two aneurysms were present in 6 of the 102 necropsy cases of Schlichter et al. (1954) and in 2 of the 80 cases of Dubnow et al. (1965).

The cavity of an aneurysm often contains mural thrombus, sometimes in sufficient quantity almost to fill it. Schlichter et al. (1954), Bailey et al. (1958), Yater, Traum, Brown, Fitzgerald,
Geisler, and Wilcox (1948), Telling and Wooler $\stackrel{\overrightarrow{\mathrm{N}}}{\stackrel{\vec{\rho}}{*}}$ (1961), and most of the more recent writers have stressed the high incidence of mural thrombosis found in ventricular aneurysms at necropsy, and $\bar{\omega}$ calcification of the clot may occur on rare occa- $\mathbb{D}$ sions (Schlichter et al., 1954 ; Edwards, 1961). Thus mural thrombosis was present in $65 \%$ of the necropsy cases reported by Dubnow et al. (1965) $\vec{\circ}$ and in $68 \%$ of the 40 cases reported by Edwards $\overrightarrow{\vec{\omega}}$ (1961). At operation mural thrombi have been $\stackrel{\omega}{\omega}$ found almost universally (Lillehei et al., 1962 ; $\vec{x}$ Cooley et al., 1964), and they were plentiful in $\underset{\sim}{\times}$ the writer's case.

The high incidence of mural thrombosis in the $\stackrel{+}{-}$ aneurysmal sac is probably related to three factors, $\vec{\infty}$ namely, endocardial damage by infarction or 을 injury, stasis within the aneurysm, and increased coagulability of the blood after myocardial infarc- 3 tion or injury. Martinova (1960) reported increased $\frac{2}{3}$ coagulability of the blood even after the relief of $\stackrel{\circ}{\triangle}$ an aneurysm by surgery.

In contrast to the above views, Abrams et al. 6 (1963) found mural thrombi in the sac in only 90 of 65 aneurysms at necropsy. They considered that this relatively low incidence might have been due to anticoagulant treatment, which many of these cases had had during life, though detailed evalua- $\frac{}{\Phi}$ tion of this treatment was not possible. In the series of Dubnow et al. (1965) 22 of the patients had had anticoagulant therapy, yet more than one half of these had mural thrombi at necropsy. In the writer's case the aneurysm contained considerable amounts of thrombus, and histologically $\vec{\partial}$ some of this was of fairly recent appearance, despite the fact that the patient had been on anti- $\stackrel{x}{\circ}$ coagulant therapy (phenindione 50 to $100 \mathrm{mg}$. b.d.) since the time of his deep vein thrombosis 13 days after his myocardial infarction.

The high incidence of mural thrombi reported 0 by most workers, both at operation and at necropsy, correlates with the substantial incidence of systemic embolism found in this disease.

The pericardium overlying the aneurysm is $\%$ often thickened and densely adherent to the N aneurysm. Calcification may occasionally occur in N the wall of the aneurysm (Schlichter et al., 1954 ; $\sigma$ Lyons and Perkins, 1958 ; Björk, 1964 ; Epstein, 1953 ; Hanbury, 1957 ; Abrams et al., 1963 ; Edwards, 1961 ; Dubnow et al., 1965 ; Telling and $\stackrel{\oplus}{\oplus}$ Wooler, 1961), and seems to be a good augury (Telling and Wooler, 1961).

At operation it may be difficult to recognize $\frac{\vec{\rho}}{\stackrel{D}{D}}$ the limits of the aneurysm and its demarcation $\vec{\nabla}$ from the rest of the ventricle before the aneurysm is opened, but once this is done recognition of the 
line of demarcation can easily be made by palpation in the case of fibrous-walled aneurysms. The tough fibrous tissue forming the aneurysm is thinner and of a different consistency from that of the surrounding ventricular wall, and the demarcation is sharp and easy to determine, as it was in the writer's case. Presumably considerable difficulty would be experienced in the case of muscular or fibro-muscular aneurysms. When the heart is inspected from the outside one may get the impression that the whole or most of the left ventricle is aneurysmal, but after resecting the sac sufficient ventricle usually remains for satisfactory closure and function.

In cases of ventricular aneurysm the heart weight is usually increased. Dubnow et al. (1965) found the weight of the heant to be at least $100 \mathrm{~g}$. more than the expected weight in $83 \%$ of their necropsy cases, and expressed the view that hypertrophy may result from the presence of an aneurysm alone. This is confirmed by the experimental work of Tyson, Mandelbaum, and Shumacker (1962) in dogs for aneurysms causing systolic expansion.

\section{THE TIME OF APPEARANCE OF ANEURYSMS}

Ischaemic aneurysm usually develops in the first few weeks after myocardial infarction (Björk, 1964). In the writer's case the aneurysm was visible on the chest radiographs 27 days after the infarction. In the series of 108 aneurysms reported in 102 patients by Schlichter et al. (1954) one aneurysm was already present at necropsy in a patient who died two days after a myocardial infarct, and another was found in a patient who died 29 days after an infarct. Parkinson, Bedford, and Thomson (1938) reported the occurrence of aneurysms after one week and two months. Telling and Wooler (1961) stated that the aneurysm should be recognizable radiologically in 8 to 12 weeks and quoted Wood (1956) as saying 'the condition may be well develoned by the time the patient is allowed up for fluoroscopy'.

Cooley et al. (1964), in a review of the literature, found the aneurysms to have been recognized at times varying between 2 and 10 years after myocardial infarotion. These workers reported on 37 of their own patients who came to operation. In 26 of these patients there had been only one infarct and there were sufficient details for analysis. In these the aneurysm of the left ventricle was recognized within 1 to 24 months of infarction, with an average period of 4.2 months. Aneurysms may thus appear very soon after myocardial infarction. Kerr et al. (1961) stated that traumatic aneurysms develop fairly quickly after injury, but that their rate of subsequent enlargement is very variable and may be slow.

\section{CLINICAL FEATURES OF VENTRICULAR ANEURYSM}

LEFT VENTRICULAR FAILURE Most patients with a ventricular aneurysm, ischaemic or traumatic, have persistent left ventricular failure which requires continuous medical treatment, including frequent admissions to hospital (Schlichter et al., 1954 ; Kerr et al., 1961 ; Telling and Wooler, 1961 ; Effler et al., 1963 ; Cooley et al., 1964), and which is eventually the main or a contributory cause of death (Schlichter et al., 1954). Of the 37 patients operated upon by Cooley et al. (1964), 31 had left ventricular failure, and this was severe in all but five of them. Gorlin et al. (1967) point out that laboratory evidence of failure (vide infra) is even more common than clinical evidence, and that there is not necessarily a relationship between heart failure and cardiac enlargement; a normal or nearly normal sized heart does not exclude failure. Eleven of their 24 patients had clinical congestive heart failure. All of these, together with seven others, had raised left ventricular enddiastolic pressures, and almost all their patients had low cardiac outputs.

ANGINA PECTORIS Some patients suffer from anginal pain (Schlichter et al., 1954 ; Telling and Wooler, 1961), as one would expect in patients suffering from severe coronary arterial disease. Of the 37 patients operated upon by Cooley et al. (1964), 16 suffered from angina.

ARRHYTHMIA This is not uncommon. It may be paroxysmal (Effler et al., 1963) and is especially likely to occur in the terminal stages in association with left ventricular failure. It may take the form of conduction defects or of atrial or ventricular arrhythmia.

SYSTEMIC EMBOLISM There is difference of opinion regarding the frequency of systemic embolism, but most workers report a high incidence. It occurred in $51.9 \%$ of the patients studied at necropsy by Schlichter et al. (1954), an incidence twice as great as that found after myocardial infarction not complicated by aneurysm, and was the main cause of $21 \%$ of the deaths. Necropsy evidence of systemic embolism was found in 30 of the 80 patients studied by Dubnow et al. (1965). Nineteen of these 30 patients $(65 \%)$ also had mural thrombosis, and the emboli were responsible for death in seven patients, while they 
contributed to death in three others. The findings of Dubnow et al. (1965) supported those of Schlichter et al. (1954) that thrombo-embolic complications are a more frequent hazard with a ventricular aneurysm than with a healed myocardial infarct uncomplicated by an aneurysm. Moreover these workers found that anticoagulant therapy offered only limited protection against the development of mural thrombosis in the aneurysm or of embolism, an opinion supported by the writer's case. Twenty-two of their patients had had anticoagulant therapy, yet at necropsy more than one half of these had mural thrombi in the aneurysm, and eight of them had had thromboembolic phenomena.

The figures of Schlichter et al. (1954) are quoted by many subsequent writers, but among the 37 operated patients of Cooley et al. (1964) systemic embolism had occurred in only two, and of the 65 necropsy cases of Abrams et al. (1963) embolism had occurred in only nine $(14.3 \%)$. This reduced incidence is undoubtedly due to anticoagulant therapy, but, as pointed out above, this provided only partial cover. There is, clearly, still a definite risk of systemic embolism, and this is a serious complication when it occurs.

\section{PHYSICAL SIGNS}

Examination of the cardiovascular system may reveal no abnormalities except those associated with left ventricular or congestive heart failure or systemic hypertension. Valve lesions may also be present. The causal infarct is likely to be panmural and to be complicated by pericarditis, so that a friction sound is likely to be heard in the acute stage. Whenever a transmural infarct complicated by pericarditis occurs in the presence of any cause of left ventricular stress, such as systemic hypertension or a valve lesion, the development of a ventricular aneurysm should be anticipated.

The next important physical sign of a ventricular aneurysm is an abnormality of the cardiac impulse (Libman, 1932 ; Schlichter et al., 1954 ; Gorlin et al., 1967 ; British Medical Journal, 1967). Libman (1932) considered that the combination of pulsation above the left fifth rib, independent of the apical impulse, gallop rhythm, and a dull first heart sound was pathognomonic of cardiac aneurysms, whereas Schlichter et al. (1954) considered that a forcible cardiac impulse associated with a weak peripheral pulse was rather characteristic. A sustained, abnormal, outward impulse in systole, lasting up to the second heart sound, and felt either over the left parasternal area or in the region of the apex, appearing fo $\overrightarrow{\vec{F}}$ the first time during the week after a myocardia? infarction and persisting thereafter, affords stron presumptive evidence of a ventricular aneurysm (British Medical Journal, 1967). The finding of such an abnormal sustained impulse is especially significant in the absence of left ventricular hyperes trophy due to conditions such as systemic hyper $\overrightarrow{0}$ tension or aortic valve disease. The abnormat cardiac impulse can be confirmed by apex cardiow graphy (Gorlin et al., 1967), impulse cardiography? (Beilen and Mounsey, 1962) or kinetocardio $x$ graphy (Eddleman, Willis, Reeves, and Harrison 1953).

Gorlin et al. (1967) were able to make the diag $\vec{\infty}$ nosis of ventricular aneurysm with certainty fromo the palpatory characteristics of the precordial impulse in 8 out of 24 patients, and to suspect the diagnosis in 5 of the remainder. They found tha impulses which were double, diffuse or unusually displaced upwards or medially were of great value when present, but stressed that it is essential to examine the patient in both the left lateral and supine positions, and preferably after a period of exertion. The apex cardiogram revealed an addi tional number of abnormalities not recognized by palpation, and this raised the number of correctly suspected cases clinically to at least one half of the series. Gorlin et al. (1967) remind us that none o $\overrightarrow{\bar{B}}$ these signs is specific for an aneurysm, but tha each reflects evidence of either abnormal cardiace contraction or of an increased end-diastolie. pressure in the left ventricle, irrespective of cause Thus in coronary artery disease the findings car occur in consequence of hyperkinetic disorderš as seen with mitral incompetence due to papillarys muscle dysfunction or rupture, or of hypokinetic disorders accompanying diffuse fibrosis or exces sive hypertrophy.

It should be pointed out that abnormalities of the cardiac impulse are demonstrated by aneu $\frac{D}{0}$ rysms situated at the apex or anteriorly, but not by those located posteriorly.

Murmurs have been described by a number of writers on the subject of ventricu'ar aneurysm but they are not of great diagnostic value (Schlich ter et al., 1954). Likoff and Bailey (1955) stated that the appearance of a systolic murmur, or of $\stackrel{O}{a}$ systolic and a diastolic murmur, after myocardials infarction is suggestive of the development of an aneurysm. Five of the 24 patients reported by Gorlin et al. (1967) had pansystolic murmurs, de $\overrightarrow{\mathbb{D}}$ spite the fact that all of them were free of valve disease. These murmurs were thought to be due to dysfunction of the anterior papillary muscles 
though in none of them was mitral regurgitation demonstrated by ventriculography. As noted previously, Dubnow et al. (1965) found scarring of a papillary muscle in one third of their cases.

Five of the patients reported by Gorlin et al. (1967) exhibited paradoxical splitting of the second heart sound, one of whom had left bundle-branch block. This sign was presumed to be due to prolongation of left ventricular systolic ejection with resultant delayed closure of the aortic valve.

Thus the physical signs which should make one anticipate or suspect the development of an aneurysm after a myocardial infarot are the presence of a friction rub during the acute stage, followed soon after by the appearance of an abnormal cardiac impulse, and perhaps also of paradoxical splitting of the second heart sound or of a mitral murmur.

\section{ELECTROCARDIOGRAPHIC FEATURES}

There are three electrocardiographic features which characterize the development of a ventricular aneurysm after myocardial infarction. The first of these is a tall $\mathbf{R}$ wave in lead AVR (Goldberger and Schwartz, 1948), which is sometimes known as Goldberger's sign. The second is persistent elevation of the ST segment with $T$ inversion in leads overlying the aneurysm (Dressler and Pfeiffer, 1940 ; Schlichter, 1940 ; Ford and Levine, 1951 ; Schlichter et al., 1954; Dubnow et al., 1965 ; Gorlin et al., 1967). The third sign is afforded by small $\mathbf{R}$ waves in leads overlying the aneurysm (Myers, Klein, and Hiralzka, 1948 ; Laake, 1960). The combination of small $\mathbf{R}$ waves with elevated ST segments and inverted $T$ waves in leads overlying the aneurysm was described by Laake (1960).

Electrocardiographic changes are well seen in the writer's case (Fig. 5). Intra-ventricular conduction defects are common (Schlichter et al., 1954 ; Abrams et al., 1963 ; Dubnow et al., 1965), and various arrhythmias are not infrequent (Schlichter et al., 1954 ; Dubnow et al., 1965), but these changes are not specific for aneurysm. Most cases showed evidence of previous infarction.

Kerr et al. (1961) pointed out that in cases of traumatic aneurysm the electrocardiographic changes are confined to $\mathrm{T}$-wave inversion in leads overlying the aneurysm. Persistent segment elevation and changes in the $\mathbf{R}$ waves were not produced by these aneurysms.

Myers et al. (1948) attributed the small $R$ waves in ischaemic cases to absence of modifying potential of active tissue overlying the neck of the aneurysm and the surrounding relatively inactive, fibrotic ventricular muscle. These authors attri- buted the persistent ST segment elevation to hypertrophy of the muscle of the opposite wall of the ventricle registered through the electrically inactive aneurysm, but Grant (1957) considered that it was due to paradoxical movement in the region of the neck of the aneurysm. The latter believed that paradoxical movement can cause a current of injury.

Abrams et al. (1963) differed from most workers in finding no specific electrocardiographic pattern. The commonest finding in their patients was that of old or recent myocardial infarction, and intraventricular conduction disturbance was frequent, but elevation of the ST segment was observed in only one of their 65 cases. This is in marked contrast to the work of Gorlin et al. (1967), who found segment elevation in 16 out of their 24 patients, though in 4 of the 16 the two-step exercise test was required to elicit it. They stressed the importance of an exercise test in diagnosing the condition electrocardiographically. Care would be necessary in the performance of such a test.

In the series of Gorlin et al. (1967) the typical segment changes were found in apical and anterior aneurysms but not in inferior (posterior) or lateral ones. The electrocardiograms of three patients with muscular aneurysms, who had minimal or no fibrosis, demonstrated no ST segment elevation either at rest or after exercise.

The findings of Dubnow et al. (1965) were in agreement with those of Gorlin et al. (1967). These workers found persistent ST segment elevation in $79 \%$ of anteriorly situated aneurysms and in $50 \%$ of posteriorly situated ones.

It appears from this review that, after myocardial infarction, anteriorly situated fibrous aneurysms are commonly associated with persistent ST segment elevation and that posteriorly situated ones are less often so associated. Segment elevation does not occur with traumatic aneurysms, and it may not occur with muscular aneurysms following myocardial infarction.

\section{RADIOLOGICAL CHANGES}

Useful descriptions of the radiological changes produced by ventricular aneurysms are given by Parkinson et al. (1938, 1939), Schwedel and Gross (1939), Schlichter et al. (1954) and Kerr et al. (1961). In antero-posterior or slightly oblique views a ventricular aneurysm forms a well-circumscribed opacity projecting beyond the normal cardiac outline, whereas in the lateral view it forms a rounded or oval shadow, partially or completely superimposed upon that of the heart (Kerr et al., 1961). These features are well shown in the 
writer's case (Fig. 6). Gorlin et al. (1967) found a rough relationship between the size of the heart and that of the aneurysm, but there were exceptions, and they pointed out that congestive heart failure could occur with little or no radiological enlargement of the heart. Aneurysms situated posteriorly may not produce any characteristic radiological changes.

The radiological changes characteristic of aneurysm may be obscured by pleural effusion or thickening, or by an elevated diaphragm. In such cases tomography may be helpful.

Abrams et al. (1963) thought that ventricular aneurysms produced no characteristic radiological changes. The main feature noted by them was cardiomegaly, sometimes with disproportionate enlargement of the left ventricle, but their study was a retrospective one and most of the radiographs were taken either shortly after myocardial infarction or shortly before death.

Identification of systolic expansion of the aneurysm is important. This can be done either by screening the patient or by cineradiography. The contraction of the non-aneurysmal portion of the ventricle must also be observed. Systolic expansion may be absent if the aneurysm is full of clot, if its neck is very narrow, or if the fibrous tissue composing its wall is very tough. As already pointed out, systolic expansion may be seen in association with fibrous, fibro-muscular or muscular aneurysms.

There is very little information regarding progressive radiological enlargement of aneurysms, but that it may occur is evident from the accounts of Ellman (1934), Parkinson et al. (1938), Codounis (1948), Cooley, Henly, Amad, and Chapman (1959), and Telling and Wooler (1961). The aneurysm of the patient reported by the latter writers enlarged rapidly over a period of 12 months, and at the time of operation its dome was thin and was almost non-existent in two places.

\section{CINEVENTRICULOGRAPHY}

Cineventriculography is an important investigation which should be carried out whenever possible, and certainly before an aneurysm is excised in most cases. It is best performed by making the injection into the left ventricle, but good results can be obtained by injections made into the pulmonary artery or left atrium, and even from the right atrium (Kerr et al., 1961; Lillehei et al., 1962). Two projections are essential in order not to miss aneurysms of the lateral or septal surfaces.
Cineventriculography will prove the diagnosiso by demonstrating that the aneurysm fills from the left ventricle, and provides useful information wit regard to the position and size of the aneurysm the size of its neck, the presence or absence of clot in the aneurysm, and the presence and type of abnormal movement, such as systolic expan= sion (dyskinesis) or absence of movement (akin esis).

Mural thrombi in the aneurysm show as fillin defects or produce a mottled appearance. If a aneurysm is full of thrombus, or if its neck is ver narrow, it may not opacify, and it is important to remember that filling of an aneurysm may be delayed, so that late films must always be exposad Other suggestive features of a ventricular aneue rysm are pooling, puddling, poor mixing, and swirling of the dye.

Gorlin et al. (1967) believed that for acccurate analysis of abnormalities of movement of the ven? tricular wall frame by frame analysis of the cine $\overrightarrow{0}$ ventriculograms, with graphic plotting of moves ment, was essential. As indicated previously, they classified as aneurysms all cases showing eitheo akinesis or dyskinesis. Of 100 patients with coros nary arterial disease, uncomplicated by eithe valvar or congenital heart disease, akinesis wa demonstrated in 16 and dyskinesis in eight. These workers found that clinical observations ofte $\vec{\Phi}$ grossly under-estimated the size of aneurysms a demonstrated by cineventriculography.

\section{SELECTIVE CINE-CORONARY ARTERIOGRAPHY}

This is a useful procedure to determine both the major site or sites of coronary arterial occlusion. and to assess the condition of the remainder of the coronary bed (Effler et al., 1963; Abramß et al., 1963; Gorlin et al., 1967). Gorlin et alo (1967) showed that no aneurysm occurred without severe involvement of the main arteries, usually occlusion, local to the area. In apical aneurysm the anterior descending artery or its mediar? branch, and either the marginal branch of the leff circumflex artery or the right coronary artery N were always severely afflicted. In anterior aneu rysms the anterior descending artery or its mediarb branch was always so affected, and in inferio aneurysms both the right coronary and circum flex arteries were always affected. Thus occlusiono or marked narrowing of the major local coronaryo artery is essential to the pathogenesis of an aneu rysm. In the necropsy study of Dubnow et al ${ }_{\mathbb{D}}$ (1965) severe coronary atherosclerosis was presenf in all 80 hearts, and in most of them severe ok 
occlusive lesions of equal degree were present in more than one major coronary artery.

In addition to the demonstration of marked narrowing or occlusion of appropriate coronary arteries selective cine-coronary arteriography shows other changes diagnostic of a ventricular aneurysm. There is marked paucity of the coronary arterial distribution to the area of the aneurysm, and the coronary arteries often end abruptly, or become thinned out with wispy branches at the edge of the aneurysm, leaving avascular gaps, particularly between the anterior descending and circumflex branches of the left coronary artery. Branches tend to arise at rightangles to the main arteries skirting the cicatricial region. The angle between the anterior descending and circumflex arteries may be widened by distortion of the myocardium between them.

\section{CLINICAL RECOGNITION OF VENTRICULAR ANEURYSMS}

Abrams et al. (1963), on the basis of a necropsy study of 65 cases of ventricular aneurysm, 63 of them due to myocardial infarction, considered that there was no consistent clinical, radiological or electrocardiographic picture characteristic of the condition, and only four of the aneurysms were diagnosed before death. These workers stated '... the diagnosis remains strikingly elusive, even in a hospital where the staff is relatively alert to this condition. The clinical signs and symptoms did not focus attention on the possibility of a ventricular aneurysm, chronic progressive heart failure and systemic embolism were infrequent, pansystolic murmurs, though heard, had little diagnostic impact, abnormalities of cardiac impulse were not noted, and the radiological and electrocardiographic changes were not typical'. These views were in conflict with those of most other writers, including Schlichter et al. (1954), who stated '. . . the diagnosis of aneurysm is rarely missed clinically ... ', and who go on to say, 'The diagnosis should be made because of the prognostic importance and because of the possibility of treatment to prevent some of the sequelae'. With this view the writer is in entire agreement, especially now that better diagnostic methods, anticoagulant therapy, and curative surgery are available. Thus Gorlin et al. (1967) found some important objective clinical clue suggestive of aneurysm in 19 of their 24 clinical cases, and the diagnosis presented no difficulty in the writer's case.

Aneurysms are difficult to diagnose clinically when they occupy the inferior, lateral or septal wall of the left ventricle, but the common anterior and apical ones can be suspected in $80 \%$ of cases after clinical, electrocardiographic, and radiographic examination, and almost all aneurysms, wherever situated, can be diagnosed by selective cineventriculography.

\section{HAEMODYNAMIC UPSET CAUSED BY VENTRICULAR ANEURYSMS}

Ventricular aneurysms cause a severe haemodynamic upset independent of that due to coronary artery disease and its associated myocardial ischaemia. Two principal causes of this upset are discussed by writers on the subject, namely:

1. Increase in the diameter of the ventricle ;

2. The presence of an expansion chamber which receives part of the left ventricular output in systole, and ejects back part of its contents into the ventricle during diastole. This occurs with paradoxical aneurysms and results in a haemodynamic upset equivalent to that of combined mitral and aortic regurgitation (Parkinson et al., 1938 ; Kerr et al., 1961 ; Tyson et al., 1962).

Increase in the diameter of a ventricle was thought to be a cause of upset to its function by assuming that the physical law of Laplace applied to the functioning heart. This law states that to maintain identical pressures within two spheres of unequal size tension in the wall of the larger sphere must exceed that in the wall of the smaller sphere by proportionally more than the difference in their radii (Tyson et al., 1962). By applying this law to the heart Burch, Ray, and Cronvich (1952) and Burton (1957) calculated mathematically that a left ventricle of twice normal diameter must generate four times its normal force in order to maintain a normal systolic blood pressure.

The causes of haemodynamic upset just discussed were investigated by Tyson et al. (1962) and Austen, Tsunekawa, Bender, Ebert, and Morrow (1962). The former workers studied the effects in dogs of increasing the diameter of the left ventricle and of creating left ventricular aneurysms, both non-paradoxical and paradoxical, with the aid of total cardiopulmonary bypass. The diameter was increased by incising the ventricle and inserting patches of non-expansile woveu Teflon. Non-paradoxical aneurysms were fashioned from $30 \mathrm{~mm}$. woven Teflon arterial grafts, and paradoxical ones from fresh, homolugous aortic arch. In acute experiments the function of the left ventricle was determined by constructing left ventricular function curves (L.V.F. curves), modified from those of Sarnoff and Berg. 
lund (1954). Left ventricular stroke work (L.V.S.W.) in gram-meters is first calculated as follows :

$$
\text { L.V.S.W. }=\frac{\text { M.A.P. }- \text { M.L.A.P. } \times \text { S.V. }}{100}
$$

M.A.P. $=$ mean aortic pressure $\left(\mathrm{cm} . \mathrm{H}_{2}\right)$

M.L.A.P. $=$ mean left atrial pressure $\left(\mathrm{cm} . \mathrm{H}_{2} \mathrm{O}\right)$ $\mathrm{S} . \mathrm{V} .=$ stroke volume (ml.) (=cardiac output in $\mathrm{ml} . / \mathrm{min} . \div$ heart rate)

Left ventricular function curves are then constructed by plotting L.V.S.W. on the vertical axis against mean left atrial pressure on the horizontal axis, as shown in Figs 10a-c. When left ventricular function is disturbed the curve is shifted downwards and to the right, e.g., it is lowered (Figs 10a, b).

The acute experiments of Tyson et al. (1962) showed that:

1. Increasing the diameter of the left ventricle did not alter the L.V.F. curves.

2. Non-paradoxical aneurysms did not alter the L.V.F. curves.

3. Paradoxical aneurysms depressed markedly the L.V.F. curves.

In chronic experiments paradoxical aneurysms not only markedly depressed the L.V.F. curves, they also produced elevation of the mean left atrial pressure and an increase in heart weight.
The above experiments prove that left ventri cular function was seriously upset by paradoxicato aneurysms but that it was not upset by non-o paradoxical aneurysms or by an increase in the diameter of the ventricle.

Austen et al. (1962) constructed paradoxicabs left ventricular aneurysms in dogs from the urinary bladders of other dogs recently killed. Large and? small aneurysms, equivalent on average to 29 and $\overrightarrow{-}$ $13 \mathrm{ml} / 100 \mathrm{~g}$. heart weight respectively, wereo fashioned. They were able to demonstrate that the्ट्र aneurysms when open (e.g., in communicationi with the ventricle) depressed the L.V.F. curves effective left ventricular function, cardiac output; and mean aortic pressure in proportion to the sizeco of the aneurysm, but that when the necks of the aneurysms were clamped all parameters returned to near control levels. The reduction of forwardk cardiac output, amounting to $29 \%$ for large aneurysms and $14 \%$ for small ones, was entirely $\bar{D}$ due to a reduction of effective stroke volume, forco the heart rate was not affected.

The above experiments showed that a paradoxi cal left ventricular aneurysm greatly impaired thes function of a healthy ventricle and increased the work load of the heart, so providing a readyo explanation for the beneficial effects that are seemo to follow excision of ventricular aneurysm in $\operatorname{man}^{\circ}$

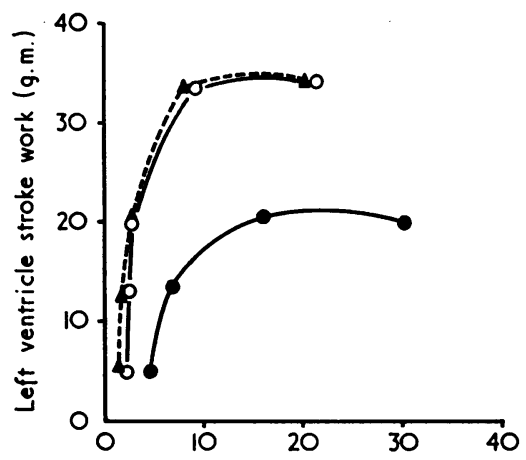

FIG. $10 \mathrm{a}$

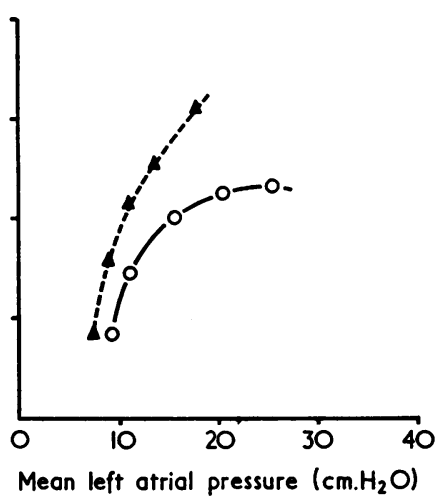

FIG. $10 \mathrm{~b}$

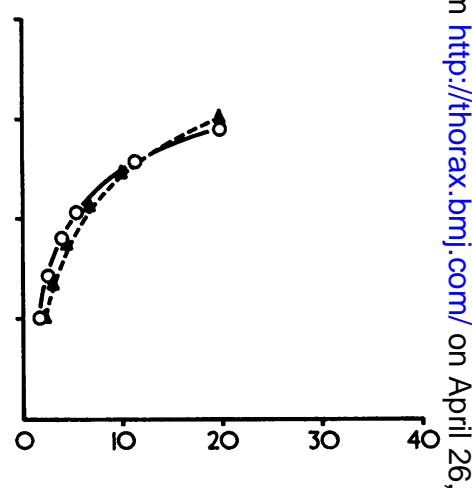

FIG. $10 c$

FIG. 10. Left ventricular function curves of a dog.

(a) An acute left ventricular aneurysm of non-expansile woven Teflon fabric: $\bigcirc-\bigcirc$ aneurysm in open communicatios with left ventricular cavity; $\Delta-\Delta$ aneurysm clamped at its base; - paradoxical exchange between aneurysm anf left ventricle manually augmented.

(b) Chronic left ventricular aneurysm of homologous aorta: $\mathbf{\Delta}-\mathbf{\Delta}$ aneurysm clamped at its base; $\bigcirc-\bigcirc$ aneurysmo in communication with left ventricle.

(c) Left ventricular diameter had been increased by insertion of a woven Teflon fabric patch graft: $\bigcirc-\bigcirc$ patch graft in place; $\mathbf{\Delta}-\mathbf{\Delta}$ edges of the incision had been approximated.

(From Tyson et al., J. thorac. cardiovasc. Surg., 44, 731-737, 1962, The C. V. Mosby Company, St. Louis, Missour

Figures 2, 4, and 5 by courtesy of the authors and publisher.) 
They also explain why the functional results following excision are best for aneurysms that show systolic expansion, a fact pointed out by several workers (Björk, 1964). This experimental work also has the merit that it has divorced the haemodynamic impairment caused by an aneurysm from that due to muscle damage resulting from coronary arterial disease. The development of a ventricular aneurysm will place a heavy burden on a myocardium already compromised by impairment of its blood supply, and this provides a sound argument in favour of the excision of such an aneurysm.

\section{VENIRICULAR ANEURYSM NOT TREATED BY SURGERY}

PROGNOSIS Schlichter et al. (1954), in a necropsy study of 2,273 proved cases of myocardial infarction, found the prognosis to be about twice as bad for those patients who developed an aneurysm of the left ventricle as for those who did not. Of those with aneurysms, $73 \%$ died within three years of infarction, and $88 \%$ of them did so within five years. By comparison, Master, Jaffe, Teich, and Brinberg (1954) found that $50 \%$ of patients who did not develop an aneurysm died within five years. These findings are very similar to those of Dubnow et al. (1965), who found a five-year survival for cases of myocardial infarction with aneurysm of $27 \%$, as compared with one of $74 \%$ for cases without aneurysm.

The bad prognosis found by Schlichter et al. (1954), and confirmed by Dubnow et al. (1965), is quoted and accepted by most subsequent writers (Lillehei et al., 1962 ; Cooley et al., 1964 ; Björk, 1964). Telling and Wooler (1961) stated 'coronary artery occlusion with aneurysm formation carries a much worse prognosis than uncomplicated coronary occlusion'. Abrams et al. (1963), on the contrary, found that the prognosis was favourable in their series of 65 cases of ventricular aneurysm studied at necropsy. Only $13.8 \%$ of their patients died in direct consequence of the aneurysm. Fifty per cent of the patients died from acute myocardial infarction, and $35 \%$ from causes unrelated to the heart. Ventricular aneurysm was not associated with markedly limited survival. The average age at death was $67 \cdot 7$ years, the average duration of survival after the first myocardial infarction was 7.2 years, and the five-year survival rate after the first myocardial infarction was $69 \%$ of the 45 patients in whom this could be determined. Abrams et al. (1963) compared these figures with those of Cole, Singian, and Katz (1954), who, working at the same hospital, studied 285 patients with myocardial infarction who did not develop ventricular aneurysms. The average age at death was 64.9 years, the average survival time after the first myocardial infarction was 8.2 years, and the five-year survival rate was $66.6 \%$. McMichael and Parry (1960), in reviewing eight studies of survival after the first myocardial infarction, found an average five-year survival rate of $65.7 \%$. Abrams et al. (1963), on the basis of these figures, concluded that the presence of a ventricular aneurysm secondary to myocardial infarction does not affect the prognosis. Their study was a necropsy one and only 4 of their 65 aneurysms were diagnosed during life. There seems little doubt that expansile infarctive aneurysms of sufficient size to be clinically manifest and to cause cardiac symptoms are associated with grave upset to health and a poor prognosis. In the series of 24 clinical cases of Gorlin et al. (1967), seven died within 2 to 10 months after study, acute myocardial infarction was the cause of death in four, cerebral haemorrhage in one, sudden death in one, and multiple pulmonary emboli in one. The remaining 17 patients survived between one and three years.

Ventricular aneurysms other than those due to myocardial infarction occurring in consequence of coronary arterial disease are rare, but the evidence indicates that the prognosis is bad. This is especially true of traumatic, and probably infective, aneurysms, in which there is a serious risk of both rupture and haemorrhage (Panday et al., 1965), as well as of ventricular failure and systemic embolism.

CAUSE OF DEATH A considerable number of patients with ventricular aneurysm die of causes unrelated to the heart. This occurred in $17.6 \%$ of the cases of Schlichter et al. (1954), in 35\% of those of Abrams et al. (1963), and in $11 \%$ of those of Dubnow et al. (1965). This is to be expected in patients of the age group that suffers from aneurysm.

In a number of the patients who die from the cardiac condition several causes contribute to death. Many patients die after a recent myocardial infarction, with or without congestive heart failure or thrombo-embolic phenomena. Death after infarction occurred in $55.9 \%$ of the patients of Schlichter et al. (1954), in $50 \%$ of those of Abrams et al. (1963), and in $42 \%$ of those of Dubnow et al. (1965). Among the 102 cases of Schlichter et al. (1954) recent infarction was the sole cause of death in $28.4 \%$, as it was of $11 \%$ of the 80 patients of Dubnow et al. (1965). Infarction after the development of an aneurysm would be expected in a significant proportion of 
patients because of their underlying severe coronary arterial disease, which was itself the cause of the aneurysm, but is probably also contributed to by the presence of the aneurysm (vide infra).

Congestive heart failure precedes or precipitates many instances of myocardial infarction or thrombo-embolism in patients with ventricular aneurysms. In the series of Schlichter et al. (1954) only one half of the recent infarcts causing death were accompanied by coronary arterial thrombosis. In the other half left ventricular failure appeared to be the cause of the infarction. This suggests that relief of the haemodynamic upset, with its consequent left ventricular failure, by surgical excision of the aneurysm might reduce the incidence of subsequent infarction. This may well be an indication for excision of these aneurysms.

Congestive heart failure was considered to be the main or a contributory cause of death in $69.7 \%$ of cases by Schlichter et al. (1954), and to be solely responsible in $14.7 \%$. In the series of Dubnow et al. (1965) congestive heart failure was considered to be the direct cause of death in $57.5 \%$ and a contributory cause in $17.5 \%$ of the patients. Seven of the 65 patients reported by Abrams et al. (1963) died from left ventricular failure. In all surgically treated series reported the incidence of left ventricular or congestive heart failure has been high prior to the operation (Cooley et al., 1964 ; Lillehei et al., 1962). It is true to say that most patients suffering from left ventricular aneurysms experience left ventricular or congestive heart failure, which is usually persistent, which is frequently the main or a contributory cause of death, and which may well predispose to acute myocardial infarction.

Thrombo-embolic phenomena were the main cause of death in $21.6 \%$ of the 102 necropsy cases reported by Schlichter et al. (1954), and were a contributory cause in $13.7 \%$ in addition. Dubnow et al. (1965) found thrombo-embolism to be the direct cause of death in $9 \%$ of their 80 patients at necropsy, and to be a contributory cause in $4 \%$, while Telling and Wooler (1961) considered that embolism was probably the cause of death in 10 to $15 \%$ of cases. In 1958 Lyons and Perkins stressed the serious risk of systemic embolism. The figures just quoted are in contrast to those of Abrams et al. (1963), who found no death due to systemic embolism among their 65 necropsy cases, and of Gorlin et al. (1967), none of whose 24 patients studied clinically died of systemic embolism. As indicated previously, the reduced incidence and mortality of thrombo-embolic phenomena in the more recently published series is probably due to anticoagulant therapy, but 0 Dubnow et al. (1965) warned that this therapy affords only partial protection (vide supra), and $\frac{\bar{s}}{\vec{D}}$ this warning should be heeded. The use of anti- $\stackrel{\mathbb{Q}}{\varrho}$ coagulant therapy in the acute stage of myocardial infarction is still controversial, and some $\vec{\circ}$ believe that the presence of a pericardial friction rub contra-indicates this form of treatment be- $\overrightarrow{\vec{\omega}}$ cause it may predispose to a fatal haemoperi- $\stackrel{\circ}{\circ}$ cardium (Hamer, 1968).

Rupture is common in traumatic aneurysms i (Kerr et al., 1961; Panday et al., 1965), and $\stackrel{+}{+}$ probably in infective ones, but is rare in those following myocardial infarction (Kerr et al., $1961 ; \stackrel{\infty}{\infty}$ Effler et al., 1963 ; Abrams et al., 1963 ; Björk, 은 1964 ; Cooley et al., 1964 ; Dubnow et al., 1965). When it does occur in the latter type of aneurysm 3 it does so early (Abrams et al., 1963), usually

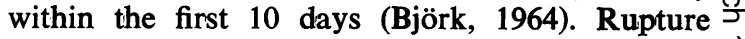
occurred in only 9 out of 150 cases reponted by $\vec{\oplus}$ Appelbaum and Nicolson (1935), and in one of 8 the 80 cases described by Dubnow et al. (1965). Three of the 65 cases reported by Abrams et al. (1963) died from rupture, but one of these was a

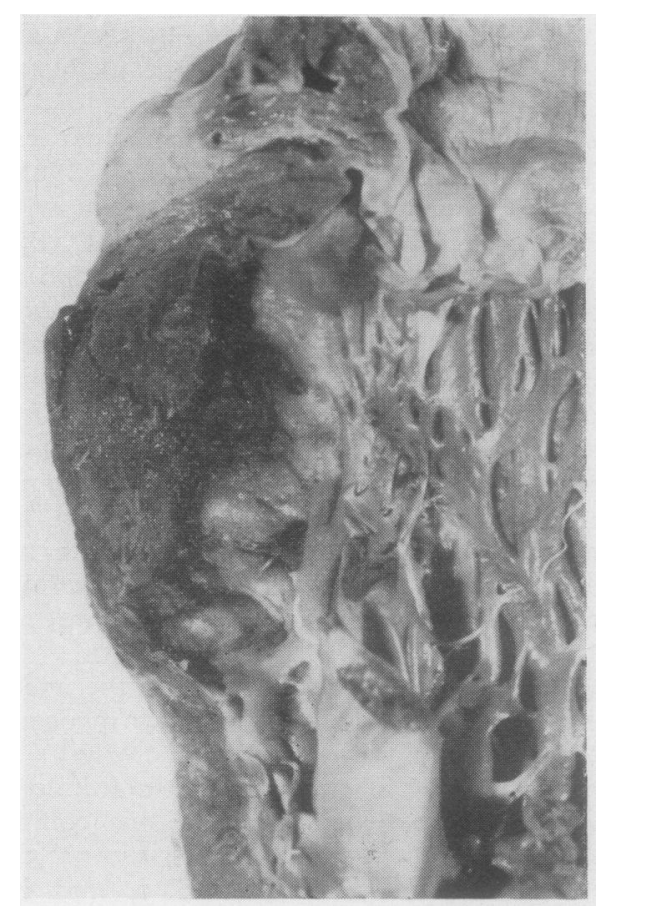

FIG. 11. Late rupture of a fibrous-walled left ventricular aneurysm resulting in death from acute cardiac tamponade. 
case of mycotic aneurysm. Figure 11 (for which I am indebted to Dr. R. M. E. Seal) illustrates the unusual occurrence of late rupture of a fibrouswalled aneurysm due to myocardial infarction in a woman aged 64 years. At necropsy there was a tense haemopericardium caused by rupture of an aneurysm, $2 \mathrm{~cm}$. in diameter, situated on the postero-lateral aspect of the left ventricle. Rupture of the thinnest part of the wall of the aneurysm, and a fracture line through the thick layer of thrombus occupying its cavity, can be seen. At the edge of the aneurysm there was obvious myocardial fibrosis resulting from previous infarction, and moderate coronary atheroma was present. Histology showed the wall of the aneurysm to be composed of collagen, with 'islands' of myocardium, and the presence of haemosiderin-laden macrophages and occasional collections of lymphocytes. There was no evidence of endocarditis, and the Gram stain demonstrated no microorganisms.

It is olear from the above analysis that left ventricular failure and recent myocardial infarction, either singly or together, account for most of the deaths in patients not treated surgically, that thrombo-embolic deaths appear to be reduced but not eliminated, by anticoagulant therapy, and that rupture is a rare cause of death, except in aneurysms due to injury or infection. Some recent infarctions are probably caused by left ventricular failure. A significant proportion of patients with ventricular aneurysms die from causes not related to the heart.

\section{INDICATIONS FOR SURGERY}

A perusal of the review of ventricular aneurysm given in the preceding pages indicates that there is considerable difference of opinion over many aspects of this condition, including its influence on the course of events after myocardial infarction. The writer, however, believes that there is much evidence to show that the development of an aneurysm is commonly attended by distressing symptoms, that it imposes a severe haemodynamic stress upon its parent ventricle, and that it jeopardizes life and increases mortality. If this be true, then there is a sound argument in favour of excising these aneurysms provided that this can be done with a reasonable mortality. The evidence suggests that this is so, and the writer, therefore, maintains that all diagnosed ventricular aneurysms should be considered with a view to surgical resection.
It is my view that paradoxical ventricular aneurysms associated with distressing symptoms or serious complications should be excised, unless surgery is contra-indicated for other reasons, such as age or concomitant disease. Old age alone, as in other conditions, is not necessarily a contraindication to surgery. In the series of 37 patients operated upon by Cooley et al. (1964), 10 were over 60 years of age, and 2 were over 70 years of age.

The features which indicate surgical excision of a ventricular aneurysm are systolic expansion, progressive increase in size, persistent or recurrent left ventricular failure not responsive to medical treatment, persistent anginal pain, systolic embolism despite good anticoagulant treatment, and haemorrhage, provided survival is long enough to allow intervention. As already mentioned, anticoagulant therapy reduces the risk of systemic embolism but does not eliminate it. Excision of the aneurysm, and therefore the source of mural thrombosis, should give protection.

The demonstration of coronary arteriosclerosis in arteries supplying regions other than those occupied by the aneurysm does not, in my view, contra-indicate excision of the aneurysm. Such a finding is the rule and must be accepted as such. The severely compromised blood supply to the myocardium which exists as the result of widespread coronary arterial disease can only be worsened by the haemodynamic load imposed by the aneurysm, and the left ventricular failure which this so often produces. Excision of the aneurysm will relieve these burdens and so improve the already impaired blood supply to the heart. As pointed out previously, Schlichter et al. (1954) found that about one half of the infarcts that occurred after the development of a ventricular aneurysm were probably caused by left ventricular failure, and not by further episodes of coronary occlusion. It may well be that the excision of ventricular aneurysm may reduce the incidence, all too high, of subsequent myocardial infarctions.

TIME FOR SURGERY Surgery should be deferred until time has been allowed for the wall of the aneurysm to be converted into tough fibrous tissue which will hold sutures securely. This takes about two to three months. From this point of view, therefore, surgery should not be performed for three months after the myocardial infarction. It has been shown that the mortality of any type of surgical operation is high soon after a myocardial infarction, and that it decreases during the first 
year. It is probably wise, therefore, to wait longer than three months if the patient's life is not in jeopardy from the haemodynamic effects of the aneurysm. However, it is of interest to know that of the 37 patients submitted to surgery by Cooley et al. (1964), the operation was performed between two and six months after the infarction in 19 of them. It thus appears to be practicable to operate at this relatively early period after myocardial infarction under the favourable conditions afforded by total cardiopulmonary bypass.

TYPES OF SURGICAL TREATMENT Prior to the advent of open-heart surgery with the aid of total cardiopulmonary bypass or deep hypothermia closed operations for aneurysm of the ventricle were employed on a number of occasions. As these methods are now historical they will be mentioned but not described. They comprise external reinforcement and closed excision beyond clamps.

External reinforcement of aneurysms has been practised using various materials, including pericardium, fascia lata, omentum, intercostal muscle, diaphragm, and skin (Lillehei et al., 1962 ; Panday et al., 1965). The method was first employed by Beck (1944), who used pericardium and fascia lata. Including the case of Panday et al. (1965), this method has been reported in 25 cases. The initial mortality was low, $8 \%$ of those collected by Lillehei $e t$ al. (1962), but there was a risk of recurrence (Panday et al., 1965). Few long-term follow-up studies are available for this type of procedure.

Closed excision beyond clamps was the method used by Sauerbruch (1931) in the first aneurysm ever to be resected (vide supra). This method was used by Likoff and Bailey (1955) and Bailey et al. (1958). The latter writers reported six cases without an operative death.

Open excision of ventricular aneurysms with the aid of total cardiopulmonary bypass or deep hypothermia is now the method of choice. Cardiopu'monary bypass was used in the writer's case, and in most of those reported, and is a very satisfactory technique. A careful and meticulous excision and repair can be performed without hurry. The first excision performed in this way was reported by Cooley et al. (1958). Since then there have been numerous reports of series or single cases, including those of Kerr et al. (1961), Lillehei et al. (1962), Telling and Wooler (1961), Effler et al. (1963), Stansel et al. (1963), Cooley et al. (1964), Björk (1964, 1965), Panday et al. (1965), and Robicsek et al. (1966).
T A B L E

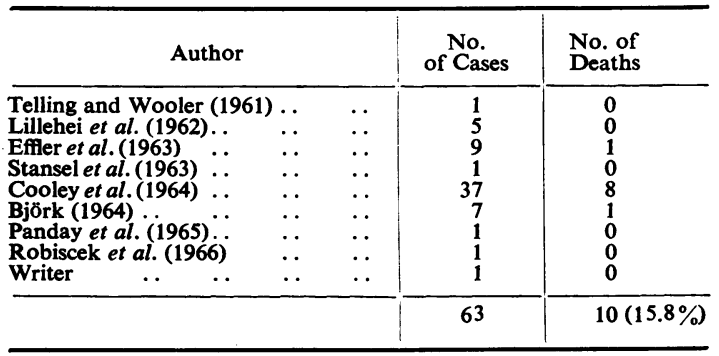

OPEN EXCISION OF VENTRICULAR ANEURYSMS

Hospital mortality The writer has collected the results of 63 open excisions, including his own. These are shown in the Table.

These cases include many of the earliest to be operated upon, so that the hospital mortality figure of $15.8 \%$ is an encouraging one, and it can be surmised that at the present time it probably does not exceed $10 \%$. The figure will obviously be modified by the type of patient chosen for surgery. In the writer's opinion, this hospital mortality is an acceptable one provided reasonable benefits accrue to most patients. This appears to be the case.

Late mortality So far there are too few late follow-up studies to allow of satisfactory conclusions. Of the nine patients operated upon by Effler et al. (1963), one died two and a half months after operation from a myocardial infarct. Twenty-nine of the 37 patients reported by Cooley et al. (1964) survived surgery. One of these developed an embolus which resulted in permanent right-sided hemiplegia and aphasia, despite embolectomy. This is the only instance of late post-operative embolism of which the writer is aware. Five of the 29 survivors died at intervals of between five months and two years after operation of causes related to ischaemic heart disease. A proportion of late deaths due to coronary heart disease is to be expected. It remains $N$ for the future to determine how big this proportion is.

The quality of life in survivors A striking decrease in the size of the heart following operation is 0 common and is well seen in the radiographs of the writer's patient taken after the operation $\stackrel{\mathcal{Q}}{+}$ (Fig. 9). Symptoms of left ventricular failure and 0 angina pectoris are greatly improved, and the $\bar{O}$ incidence of embolism appears to be low. Among the 29 survivors following surgery in the series of $\mathbb{\mathbb { D }}$ Cooley et al. (1964) there was significant improvement of congestive heart failure and angina in all 
of them, only one experienced an embolus, 18 returned to work, and 10 to active retirement. No recurrent aneurysms occurred. In the series reported by Effler et al. (1963) eight out of nine survived surgery, and one of these died two and a half months after operation from myocardial infarction. The remaining seven survivors were all uniformly improved. Six of the seven patients of Björk (1964) survived surgery. One remained well for one and a half years and then developed a false aneurysm through the suture line. He died after re-operation. Four of the remaining five were significantly improved, but the other was not improved.

The somewhat meagre information which is available suggests that the excision of ventricular aneurysms greatly relieves those patients who survive surgery from the burdens of left ventricular failure, anginal pain, and systemic embolism, but the risks of the underlying coronary arterial disease remain and account for a proportion of late deaths. As indicated earlier, it is hoped that this risk will be reduced by excision of the aneurysm.

CARDIAC CATHETERIZATION STUDIES BEFORE AND AFTER SURGERY The relatively few catheterization studies performed before and after excision of ventricular aneurysm support the hypothesis that relief of symptoms results from improved ventricular function. Eighteen of the 37 patients submitted to surgery, and reported by Cooley et al. (1964), were catheterized pre-operatively. Most of the patients showed elevated pulmonary wedge, pulmonary arterial, and right ventricular pressures together with reduced cardiac indices. The cardiac index ranged from 1.5 to $5.31 . / \mathrm{min} . / \mathrm{m}^{2}$ Seven of the patients were re-catheterized at periods varying between six weeks and five years after the operation. In all of them the right heart pressures had returned to normal. The cardiac indices were unchanged in two, increased by $50 \%$ in two, and increased by $100 \%$ or more in three patients.

These catheter studies provide further proof that ventricular aneurysms do cause a haemodynamic upset, and that this may be relieved by surgical excision.

My thanks are due to Dr. G. S. Kilpatrick for his kindness in asking me to see this case, and for his help and encouragement in the preparation of this paper.

\section{BIBLIOGRAPHY}

Abrams, D. L., Edelist, A., Luria, M. H., and Miller, A. J. (1963) Ventricular aneurysm. A reappraisal based on a study of sixty-five consecutive autopsied cases. Circulation, 27, 164

Appelbaum, E., and Nicolson, G. H. B. (1935). Occlusive diseases of the coronary arteries; an analysis of the pathological anatomy in 168 cases, with electrocardiographic correlation in 36 of these. Amer. Fieart J., 10, 662.
Austen, W. G. Tsunekawa, T., Bender, H. W., Ebert, P. A., and Morrow, A. G. (1962). The acute haemodynamic effects of left ventricular aneurysm. An experimental study in dogs. J. surg. Res. , 2, 161 .

Bailey, C. P., Bolton, H. E., Nichols, H., and Gilman, R. A. (1958). Ventriculoplasty for cardiac aneurysm. J. thorac. Surg., 35, 37.

Barber, H. (1944). The effects of trauma, direct and indirect, on the heart. Ouart. J. Med., n.s. 13, 137.

Beck, C. S. (1944). Operation for aneurysm of the heart. Ann. Surg., 120,34 .

Beilin, L., and Mounsey, P. (1962). The left ventricular impulse in hypertensive heart disease. Brit. Heart J., 24, 409.

Björk, V. O. (1964). Ventricular aneurysm. Thorax, 19, 162. (1965), Congenital left ventricular aneurysm. lbid., 20, 190.

Bright, E. F., and Beck, C. S. (1935). Non penetrating wounds of the heart; a clinical and experimental study. Amer. Heart J., 10, 293.

British Medical Journal (1967). Ventricular aneurysm (Leading article), 4, 312.

Burch, G. E., Ray, C. T., and Cronvich, J. A. (1952). Certain mechanical peculiarities of the human cardiac pump in normal and diseased states. Circulation, 5, 504.

Burton, A. C. (1957). The importance of the shape and size of the heart. Amer. Heart J., 54, 801.

Campbell, M., Deuchar, D. C., and Brock, Sir R. (1954). Results of pulmonary valvotomy and infundibular resection in 100 cases of Fallot's tetralogy. Brit. med.J., 2, 111 .

Codounis, A. (1948). Long survival with a cardiac aneurysm. Brit. Heart. J., 10, 244.

Cole, D. R., Singian, E. B., and Katz, L. N. (1954). The long-term prognosis following myocardial infarction, and some factors which affect it. Circulation, 9, 321.

Cooley, D. A., Collins, H. A., Morris, G. C., and Chapman, D. W. (1958). Ventricular aneurysm after myocardial infarction. J. Amer. med. Ass., 167, 557.

- Henly, W. S., Amad, K. H., and Chapman, D. W. (1959). Ventricular aneurysm following myocardial infarction: Results of surgical treatment. Ann. Surg., 150, 595 .

- Hallman, G. L., and Henly, W. S. (1964). Left ventricular aneurysm due to myocardial infarction. Arch. Surg., 88, 114.

Cruveilhier, J. (1827). Observations et refléxions sur une poche anévrysmale et osseuse naissant derrière le bord gauche du cœur. Bull. Soc. anat. Paris, 2, 36. Quoted by Tellig and Wooler (1961).

Derra, E., and Loogen, F. (1959). Uber Herzkammeraneurysmen bzw. Herzkammerdivertikel und ihre operative Behandlung. Dtsch. med. Wschr., 84, 1585.

Dressler, W., and Pfeiffer, R. (1940). Cardiac aneurysm: a report of 10 cases. Ann. intern. Med., 14, 100.

Dubnow, M. H., Burchell, H. B., and Titus, J. L. (1965). Postinfarction ventricular aneurysm. A clinicomorphologic and electrocardiographic study of 80 cases. Amer. Heart J., 70, 753.

Dubost, C. (1955). In discussion of pulmonary stenosis. Henry Ford Hospital International Symposium on Cardiovascular Surgery, 1955, ed. C. Lam, p. 68. Saunders, Philadelphia.

Eddleman, E. E., Willis, K., Reeves, T. J., and Harrison, T. R. (1953). The kinetocardiogram 1. Method of recording precordia movements. Circulation, 8, 269.

Edwards, J. E. (1961). An Atlas of Acquired Diseases of the Heart and Great Vessels. Vol. II. Coronary Arterial Diseases, Systemic Hypertension, Myocardiopathies, the Heart in Systemic Disease, and Cor Pulmonale, Acute and Chronic, pp. 615-629. W. B. Saunders, Philadelphia.

Effler, D. B., Westcott, R. N., Groves, L. K., and Scully, N. M. (1963). Surgical treatment of ventricular aneurysm. Arch. Surg., 87, 249.

Ellman, P. (1934). Cardiac aneurysm following myocardial infarction and coronary thrombosis (with autopsy findings). Proc. roy. Soc. Med., 27, 1468.

Epstein, F. H. (1953). Calcified ventricular aneurysm: Case report, with a note on prognosis. Amer. Heart J., 46, 150.

Ford, R. V., and Levine, H. D. (1951). The electrocardiographic clue to ventricular aneurysm. Ann. intern. Med., 34, 998.

Galeati, Dominicus Gusmanus (1757). De bononiensi scientiarum et artium instituto arque academia commentarii. De morbis duobus, $4,26$.

Goldberger, E., and Schwartz, S. P. (1948). Electrocardiographic patterns of ventricular aneurysm. Amer J. Med., 4, 243.

Gorlin, R., Klein, M. D., and Sullivan, J. M. (1967). Prospectıve correlative study of ventricular aneurysm. Mechanistic concept and clinical recognition. Ibid., 42,512 .

Grant, R. P. (1957). Clinical Electrocardiography. The Spatial Vector Approach. McGraw-Hill, New York.

Hall, D. G. (1903). Cardiac aneurysms. Edinb. med. J., N.S. 14, 322. 
Hamer, J. (1968). The diagnosis and management of coronary disease. Hosp. Med., $2,514$.

Hanbury, W. J. (1957). Calcified cardiac aneurysm. Brit. Heart J., $19,435$.

Harken, D. E. (1946). Foreign bodies in, and in relation to, the thoracic blood vessels and heart. Surg. Gynec. Obstet., 83, 117.

Hunter, J. (1757). An Account of the Dissection of Morbid Bodies (A manuscript copy in the Library of the Royal College of Surgeons), p. 30, case 32.

Joachim, H., and Mays, A. T. (1927). A case of cardiac aneurysm probably of traumatic origin. Amer. Heart J., 2, 682.

Kerr, W. F., Wilcken, D. E. L., and Steiner, R. E. (1961). Incisional aneurysms of the left ventricle. Brit. Heart J., 23, 88.

Laake, H. (1960). Postinfarction myocardial aneurysm. Acta med. scand., 167, 221.

Legg, J. W. (1884). Some Account of Cardiac Aneurysms (The Bradshawe Lecture, 1883), p. 17. Churchill, London.

Libman, E. (1932). Affections of the coronary arteries. Interest. Postgrad. Med. Ass. N. Amer., pp. 405-410.

Likoff, W., and Bailey, C. P. (1955). Ventriculoplasty: excision of myocardial aneurysm. J. Amer. med. Ass., 158, 915.

Lillehei, C. W., Levy, M. J., DeWall, R. A., and Warden, H. E. (1962) Resection of myocardial aneurysms after infarction during temporary cardiopulmonary bypass. Circulation, 26, 206.

Lurie, A. O. (1960.) Left ventricular aneurysm in the African. Brit. Heart J., 22, 181.

Lyons, C., and Perkins, R. (1958). Resection of a left ventricular aneurysm secondary to cardiac stab wound. Ann. Surg., 147, 256.

McCord, M. C., and Blount, S. G. (1955). Complications following infundibular resection in Fallot's tetralogy. Circulation, 11, 754

McMichael, J., and Parry, E. H. O. (1960). Prognosis and anticoagulant prophylaxis after coronary occlusion. Lancet, 2,991 .

Martinova, A. B. (1960). Surgical treatment of post-infarct heart aneurysm. Vestn. Khir., 85, 11.

Master, A. M., Jaffe, H. L., Teich, E. M., and Brinberg, L. (1954). Survival and rehabilitation after coronary occlusion. J. Amer. med. Ass., 156, 1552.

Miller, G., Lowenthal, M., Krause, S., and Rosenblum, P. (1953). A saccular outpouching of the right ventricle in a child visualized by angiocardiography. Amer. J. Roentgenol., 69, 69.

Myers, G. B., Klein, H. A., and Hiralzka, T. (1948). II. Correlation of electrocardiographic and pathologic findings in large anterolateral infarcts. Amer. Heart J., 36, 833.

Panday, S. R., Parulkar, G. B., Kelkar, M. D., and Sen, P. K. (1965). Recurrent haemorrhage from iatrogenic left ventricular aneurysm. Thorax, 20,510.

Parkinson, J., Bedford, D. E. and Thomson, W. A. R. (1938). Cardiac aneurysm. Quart, J. Med., n.s. 71, 455 .

_- (1939). Cardiac aneurysm. Brit. J. Radiol., 12, 129.

Phares, W. S., Edwards, J. E., and Burchell, H. B. (1953). Cardiac aneurysms: clinicopathologic studies. Proc. Mayo Clin., 28, 264

Pocock, W. A., Cockshott, W. P., Ball, P. J. A., and Steiner, R. E. (1965). Left ventricular aneurysms of uncertain aetiology. Brit. Heart J., 27, 184.

Robicsek, F., Dickson, G. C., Parke, J. C., Daugherty, H. K., and Sanger, P. W. (1966). Resection of a post-infarction aneurysm in a 4-year-old child.J. thorac. cardiovasc. Surg., $52,408$.
Rokitansky, C. (1842-44). Handbuch der pathologischen Anatomie. Vienna.

Sarnoff, S. J., and Berglund, E. (1954). Ventricular function. I Starling's law of the heart studied by means of simultaneous right and left ventricular function curves in the dog. Circulation, $9,706$.

Sauerbruch, F. (1931). Erfolgreiche operative Beseitigung eines Aneurysma der rechten Herzkammer. Arch. Klin. Chir., 167, 586.

Schlichter, J. G. (1940). Beitrag zu den Aneurysmen und Reupturen des Herzens. Thèse Presentée à la Faculté de Médecine de l'Université de Lausanne.

Schlichter, J., Hellerstein, H. K., and Katz, L. N. (1954). Aneurysm of the heart: A correlative study of one hundred and two proved cases. Medicine (Baltimore), 33, 43.

Schwedel, J. B., and Gross, H. (1939). Ventricular aneurysms. Roentgenographic and post-mortem surveys. Amer. J. Roentgenol., 41, 32 .

Segel, N., Fatti, L., Adler, D., and Crawshaw, G. R. (1957). Aortic stenosis. An evaluation of results of surgery in 20 cases. $S$. Afr. med. J., 31, 899.

Sézary, A., and Alibert, T. (1922). Anévrisme pariétal du cœur. Bull. Soc. $m$ d. Hôp. Paris, 3 Ser., 46, 172.

Smith, R. C., Goldberg, H., and Bailey, C. P. (1957). Pseudoaneurysm of the left ventricle: diagnosis by direct cardioangiography. Surgery, 42, 496.

Smithy, H. G., Boone, J. A., and Stallworth, J. M. (1950). Surgica treatment of constrictive valvular disease of the heart. Surg. Gynec. Obstet., 90, 175.

Špaček, B., Bergmann, K., and Dejdar, R. (1959). Úber die Resektion eines falschen Herzwandaneurysmas. Zbl. Chir., 84, 689.

Stansel, H. C., Julian, O. C., and Dye, W. S. (1963). Right ventricular aneurysm. A review of the literature and report of a case of successful repair with the aid of temporary cardiopulmonary bypass. J. thorac. cardiovasc. Surg., 46, 66.

Sternberg, M. (1914). Das chronische partielle Herzaneurysma. Franz Deuticke, Vienna and Leipzig.

Telling, M., and Wooler, G. H. (1961). Excision of cardiac aneurysm. Lancet, 2, 181.

Tennant R., and Wiggers, C. J. (1935). The effect of coronary occlusion on myocardial contraction. Amer. J. Physiol., 112, 351.

Thomas, C. G., and Ziffren, S. E. (1952). Healing of extensive cardiac wounds. J. thorac. Surg., 24, 346

Tyson, K., Mandelbaum, I., and Shumacker, H. B. (1962). Experimental production and study of left ventricular aneurysms. $J$. thorac. cardiovasc. Surg., 44, 731.

Vasiljevic, D., Antic, R., Tomic, L., Anojcic, S., and Prokic, D. (1959) Infarctus et anévrisme du cœur aprés une plaie pénétrante du ventricule droit. Arch. Mal Cour, 52, 1291.

Warren, W. D., Muller, W. H., East, M., and Sosa, O. (1958). Experimental study of the anatomic and physiologic effects of incisions into the left ventricle. Surg. Forum, 9, 257.

Wood, P. (1956). Diseases of the Heart and Circulation, 2nd ed. Eyre and Spottiswood, London.

Yater, W. M., Traum, A. H., Brown, W. G., Fitzgerald, R. F., Geisler, M. A., and Wilcox, B. B. (1948). Coronary artery disease in men eighteen to thirty-nine years of age. Amer. Heart J., 36, 